University of Rhode Island

DigitalCommons@URI

Open Access Dissertations

1974

\title{
The Effect of Extinction on the Delayed Learning of a Conditioned Taste Aversion in the Rat
}

John J. Colby

University of Rhode Island

Follow this and additional works at: https://digitalcommons.uri.edu/oa_diss

\section{Recommended Citation}

Colby, John J., "The Effect of Extinction on the Delayed Learning of a Conditioned Taste Aversion in the Rat" (1974). Open Access Dissertations. Paper 997.

https://digitalcommons.uri.edu/oa_diss/997

This Dissertation is brought to you for free and open access by DigitalCommons@URI. It has been accepted for inclusion in Open Access Dissertations by an authorized administrator of DigitalCommons@URI. For more information, please contact digitalcommons-group@uri.edu. 
THE EFFECT OF EXTINCTION ON THE DEIAYED LEAENING

OF A CONDITIONED TASTE AVERSION IN THE RET

$B Y$

JOHN J. COLBY

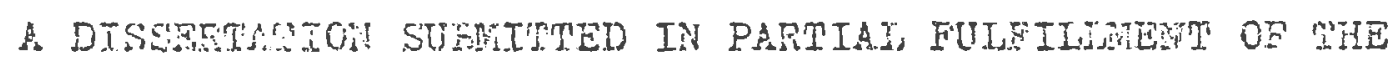
REQUTEMENAS FOR THE DEGREE OF DOCTOR OF PHIIOSOPHY

UNTVESTTY OF PEODE ISIAND

1974 


\section{ABSTRACT}

This invertigation entailed the first aystematic arajy sis of the ortinction o: a conditioned tate avereion. Tho study was udertaken because Iittit is krown about tre elimfnation of thase prepared responges.

Fropared responseg anpos to be characteriace by (I) the fornation of associztion betwoer epecifos atinuli (2) tha

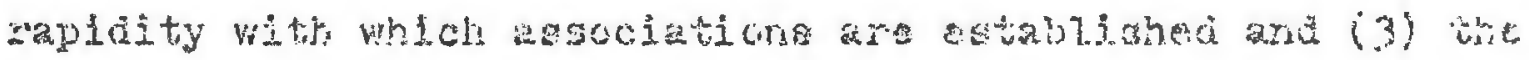

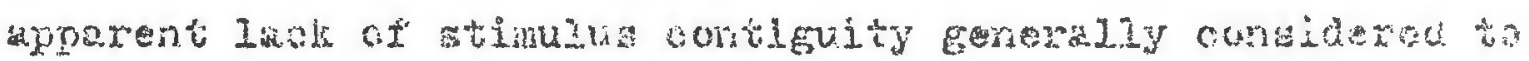

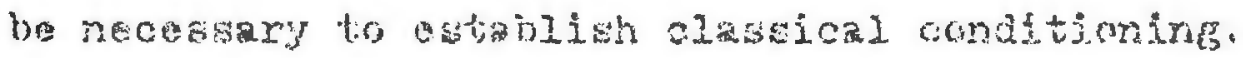

Throughout tho papar an atsempt has bech made to colm trast the acculettion and extinction prases of the condtionwa tase arersion, the prepared regponst, with the body oi

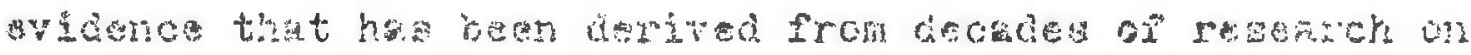
unpeparen responses with the ultimate gon of deterabine

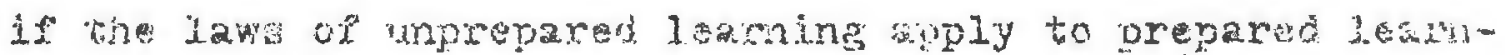

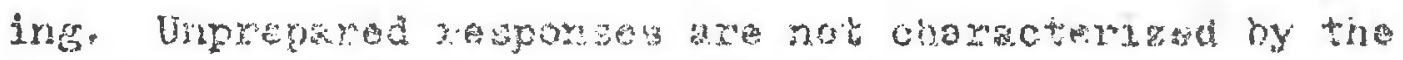

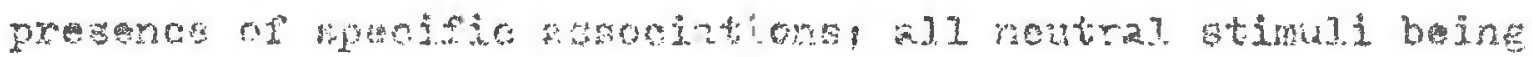
ay 
uli are repoatedly paired. Unprephed leaming is theught to reflect trial and error learning whereas prepared learnIng phenomena seem to suggest the presence of special memory mechanisms that facilitate the acquisition of adaptative responses to important events in the organitgas environment e.g: associating gustatory cues with stomach malnise. The subjects for this study were 72 male albino rats. Eighteen rats were assigned as control subjects and did not acquire the conditioned taste aversion. The romaining 54 rats were subdivided into groups of 1.8 and were al.1 made ill after consuming saccharine, a novel food. Jach of thesse four groups of 18 rats were further subdivided into three suigroups and received either 3, 5 or 10 sensitization trials (controls) or extinction trials (experimental subjeots). One group of experimental rats $(N=18)$ after baing subdividad into the three subgroups $(n=6)$ received sither 1, 5 or 10 rorced exposures to the saccharine. A secoma group of 1.3 rats after subdivision received 1,5 or 10 injections of LiCj., the ill.m ness inducing agent. The final 18 rati were an iliness retention group. The three subgroups of six rats each were nerely testea for ancharine aversion after 1, 10 or-20 cara. 


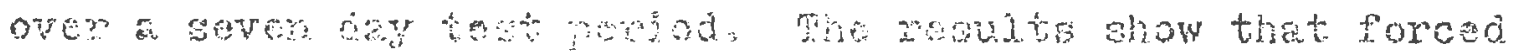

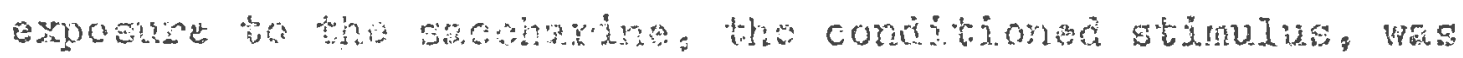

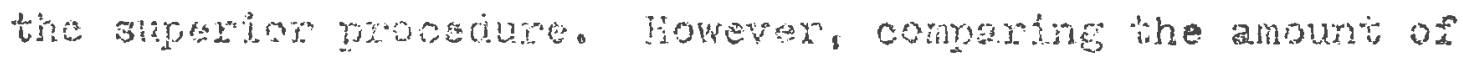

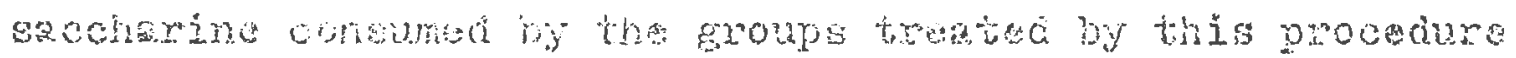

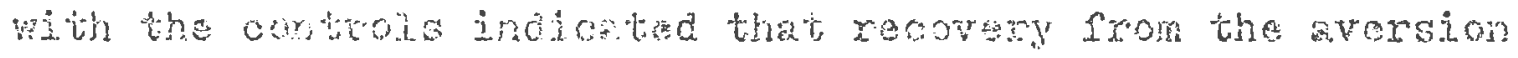

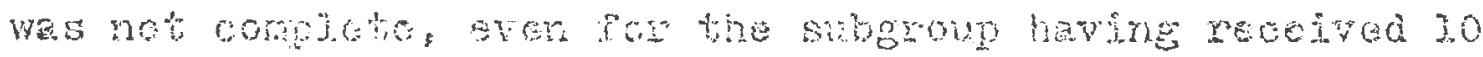
fowed topowa to sechering.

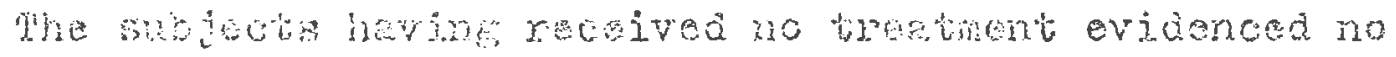

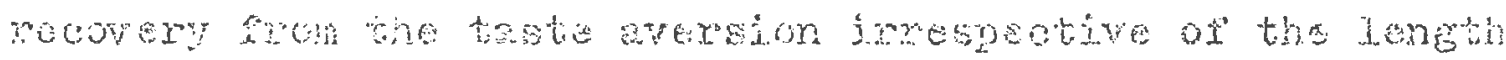

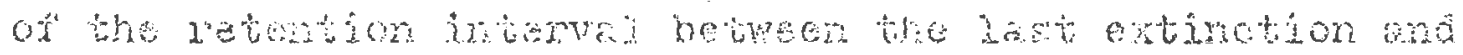

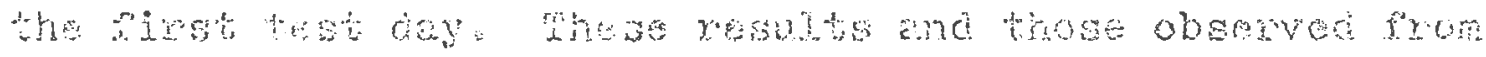

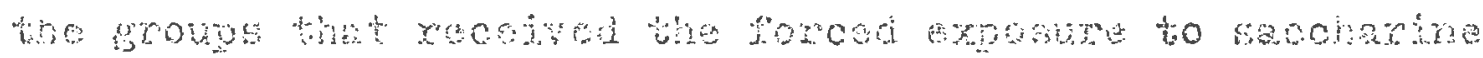

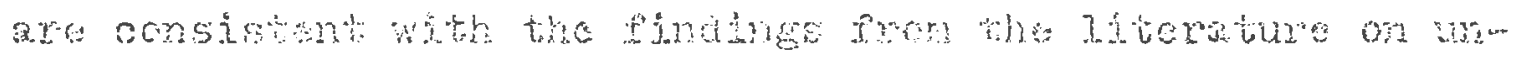

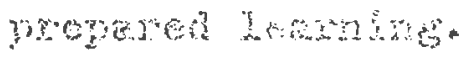

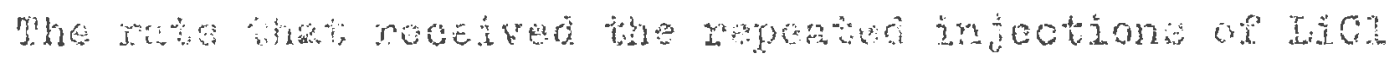

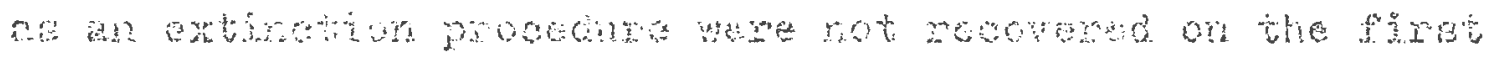

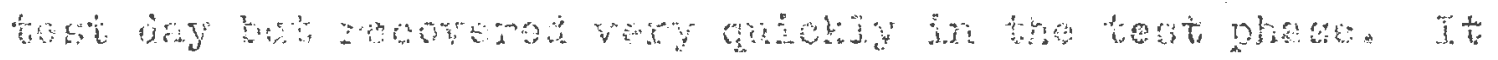

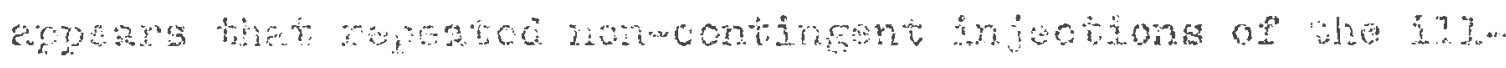

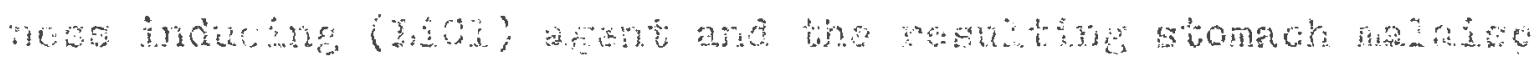

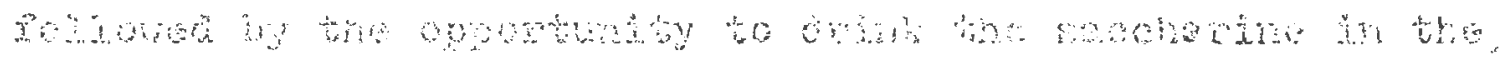

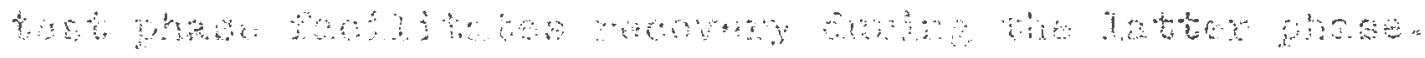

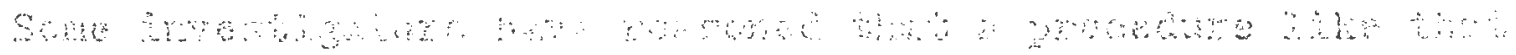


described above might contribute to the formation of cognitions which are incensistent with those formed during the acquisition phase; That is, the illness that was ascribed to the saccharine in the acquisition phase is, during the test phase no longer so ascribed because of the non-saccharino related illness of the extinction peried. This cognitien would expedite recovery when the saccharine is later presented with no subsequent iliness as is the case in the test phase. This latter result was not expected based on the sensitization data from the unprepared area of learning. 


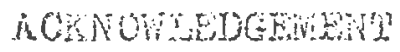

Many indivjouals have contributed to the progrese or

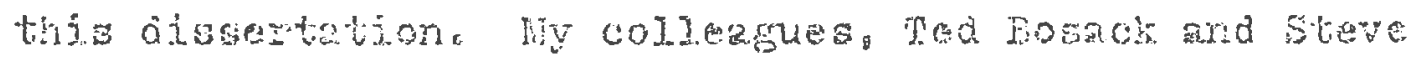

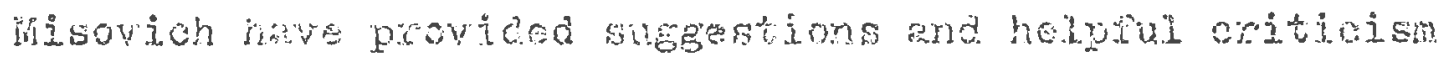

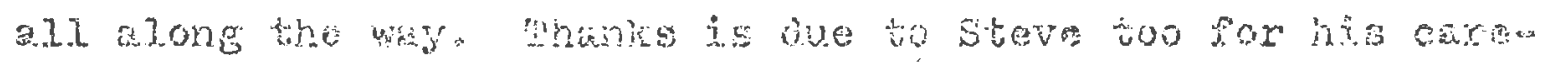

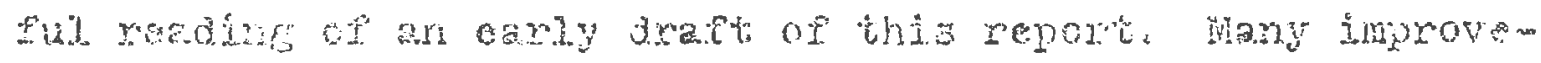

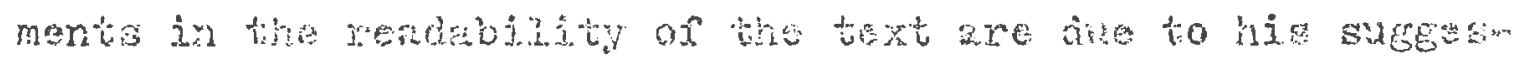
titons.

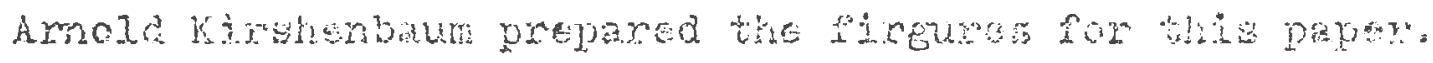


work.

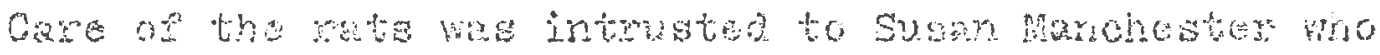

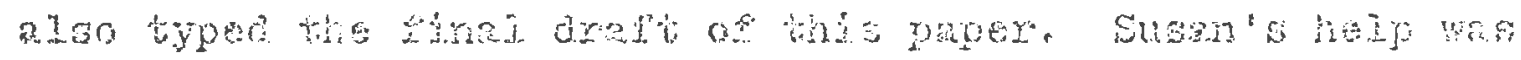

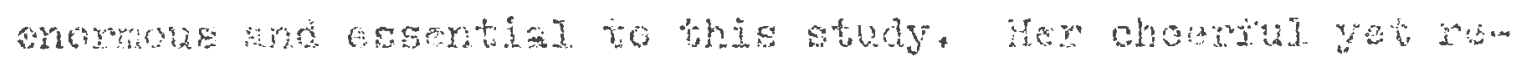

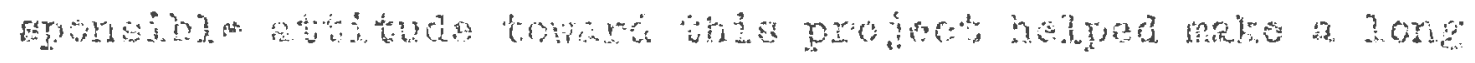

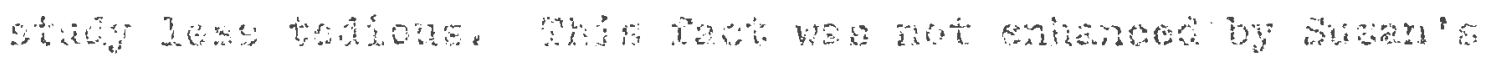

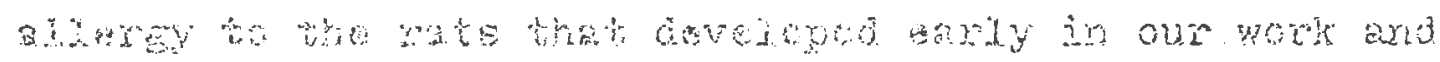

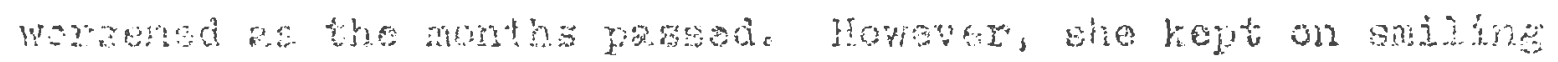

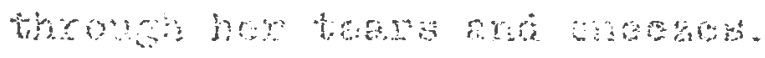

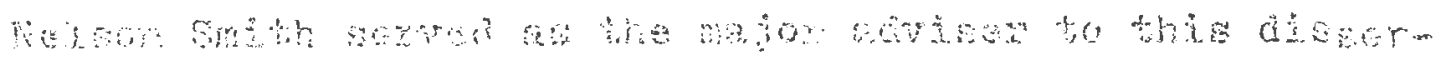

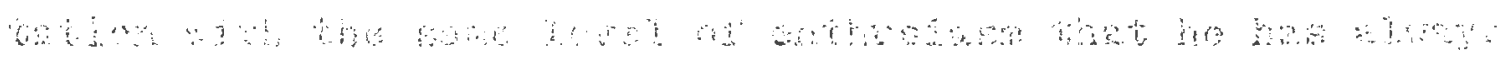




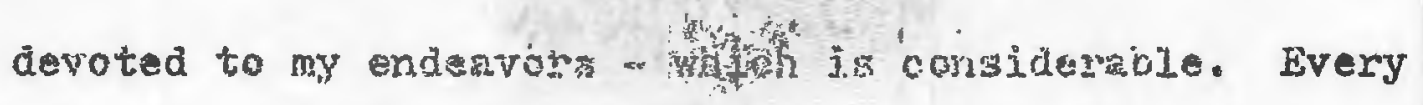

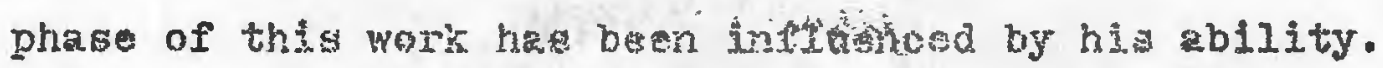
His attention to dotali has elininated many shortcomings in clarity. Where confusion remains it is not due to a lack of effort on his paxt. As important as Nelson' skilla have boan to the completion of this program, his patience ardia frisaskip havo been of even greater value to me eapecially in the early days of my tonure as a graduate student.

My wife: Lymne, has boon so supporitre of ny efforts and so giving of hergels over the period of my work that nothing I can gay can convey my appreaition and love. She and I know, however, that this is another product of our labor.

Finaliy, many of the intangibies that inspixe goneone to achieva st this lovel are probaby attributed to one's parents. I recognica and appractats the things they did long ago that influance my life today.

In conclusion. I have dedicated this work to the mom ory of my rathe who taught xs by his arame that there is no gudatitide for efrort. 
TABIE OF CONTENTS

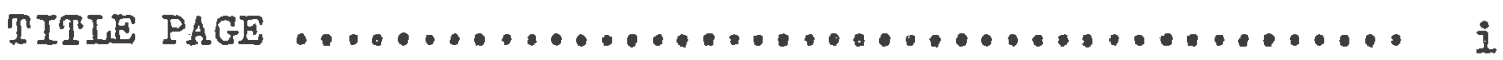

APPROVAL PAGE $\ldots \ldots \ldots \ldots \ldots \ldots \ldots \ldots \ldots \ldots \ldots \ldots \ldots \ldots \ldots \ldots \ldots$

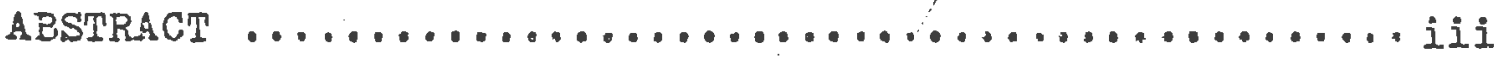

ACKNOWLEDGEMENT $\ldots \ldots \ldots \ldots \ldots \ldots \ldots \ldots \ldots \ldots \ldots \ldots$ vi

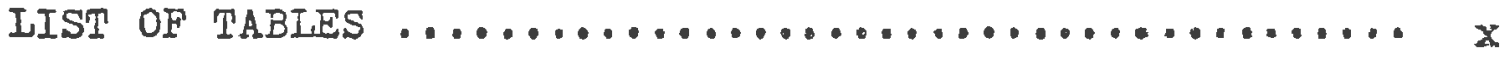

IIST OF ILLUSTRATIONS $\ldots \ldots \ldots \ldots \ldots \ldots \ldots \ldots \ldots \ldots \ldots \ldots \ldots$

CHAPTER

I. INTRODUCTION $\ldots \ldots \ldots \ldots \ldots \ldots \ldots \ldots \ldots \ldots \ldots \ldots \ldots$

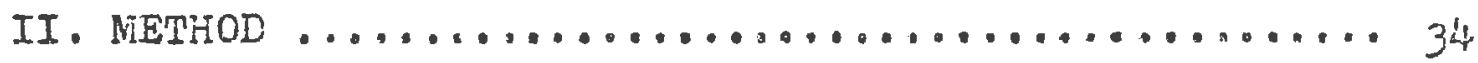

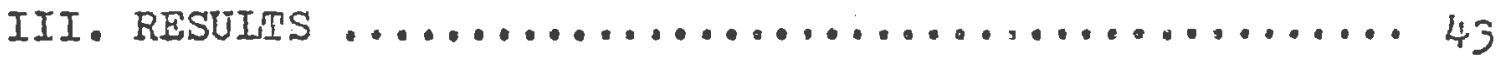

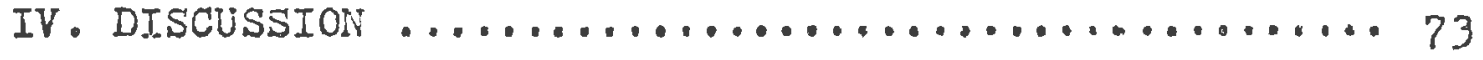

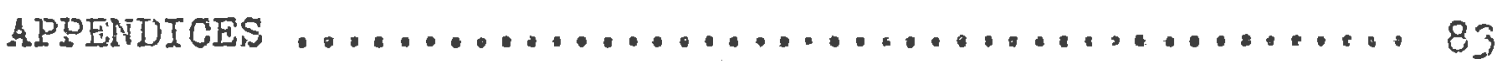

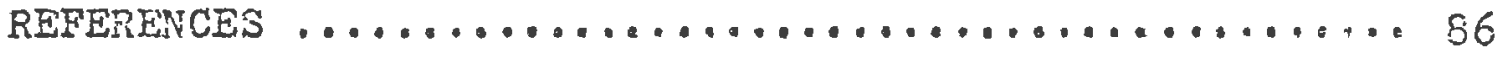




\section{LIST OF TABIES}

TABLES

Page

1. Design of the acquisition and extinction phases for the experimental and control groups........... 36

2. Mean anount of saccharine consumed (cubic centineters) on each of the three acquisition

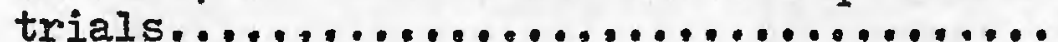

3. Mean amount of saccharine consumed (cubic centimeters) on each of seven test trials $(n=6)$ by the contrel groups.

4. Mean amourit of saccharine consumed (cubic centimeters) on each of seven test trials $(n=6)$ by the eaccharine-only groups.

5. Hean amount of saccharine consumed (cubic centimeiers) on each of seven test trials $(n=6)$ by the Iicl-only groups.

6. Wean amolint of saccharine consumed (cubic centimetexs) on each of seven test trials $(n=6)$ by the retention Eroups. 


\section{TISI OE TEMUSTRATONS}

Figure

Fُ

1. Mean amount of gecoharine convined or bets of

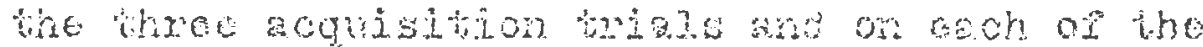
seven test inials for the contiol fatre.........

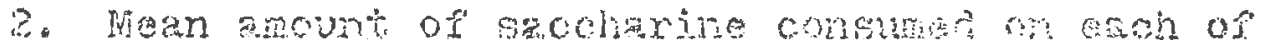
the three soguistiton trials are on ach of the

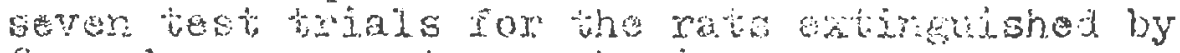

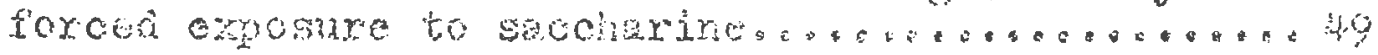

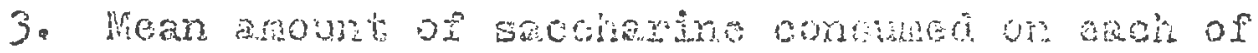

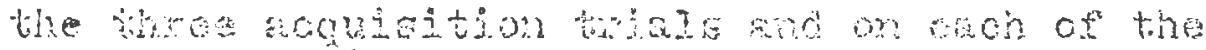

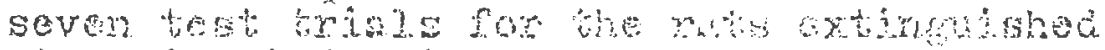

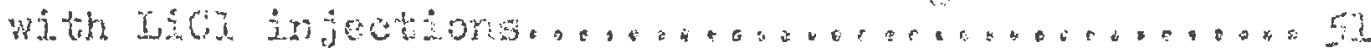

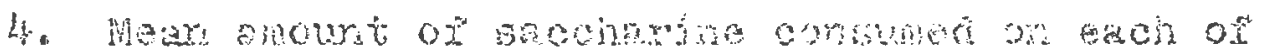



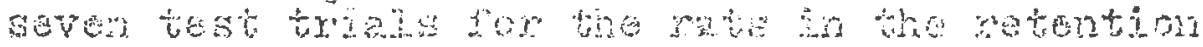

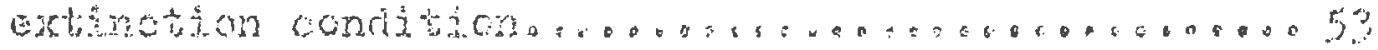

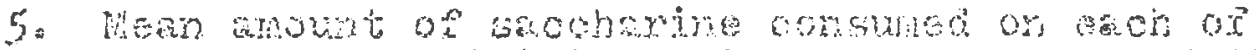

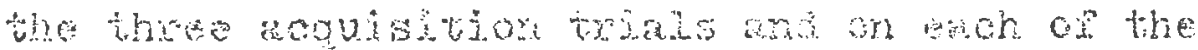

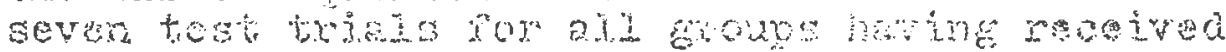

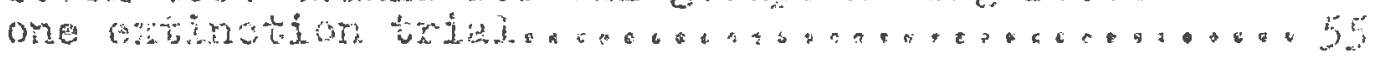



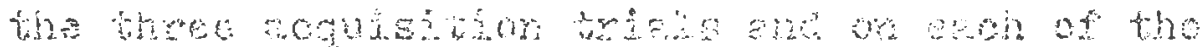

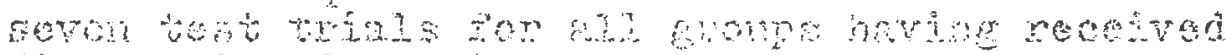

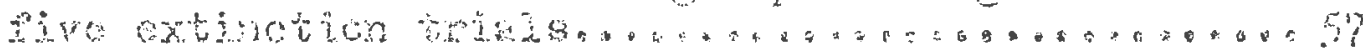

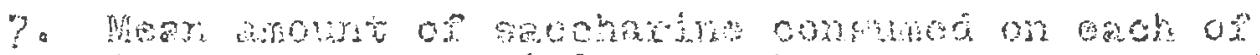

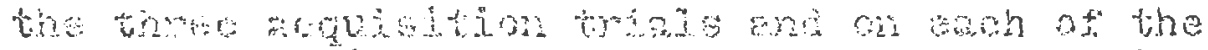

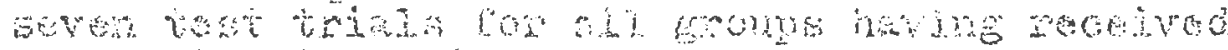

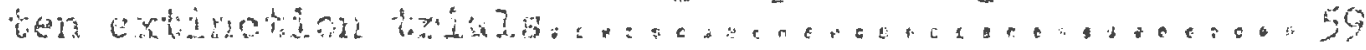




\section{INTRODUCTION}

Behaviorists have generally seceptod tho conclusion that the rat is a passive participent in learning exper ments and rorm associations botween any ats of contiguous cvents (Paviov, 2928). In a recent departure from this traition some invertigators (Greja, Kimaldorf and Hunt, 1951) heve reported regults, that chaijenge the viow that all atimulue paire are oqualy asmociable. There results suggest that the rat brings to aone learming tak speciss specific fesponse terdencies which urance the likelihood that specifio associations, not any association, will bo estarljshed between stimulus stents. Whese response tendancies art beiloved to refiect a biological acaptability to the naturel enviroment and cari be eliotted from every nustolus of the species.

Athough spocies gecific sespunse tendencies have ondy recently bess of irfereat to pryohulogists, they are

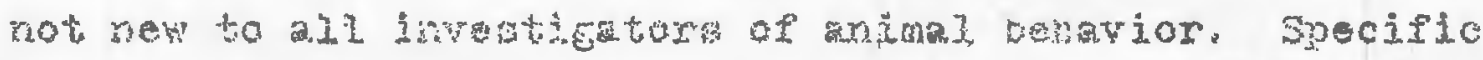




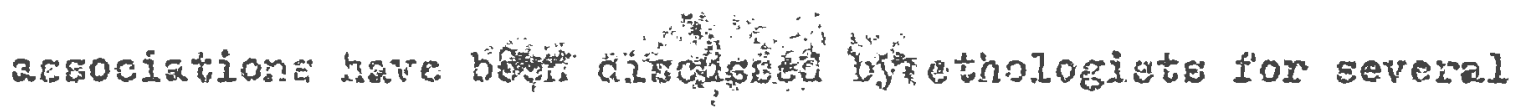
decades. Ar approxingtion to aperifo raponse tendencies has been desoribed in whomajke's Iav of Readress (1932) 2nd hag beun interpreted by Hilgard and Bower (2966) to mean an "astion tordeney".

Recentzy, sejigman and Hager (1972) developed an organ jzational wcheme that dofines the recescary conditions for specifje asaciations to be egtablithed when al. possible associations seen equally 11kely. Thxoe leaming typas have

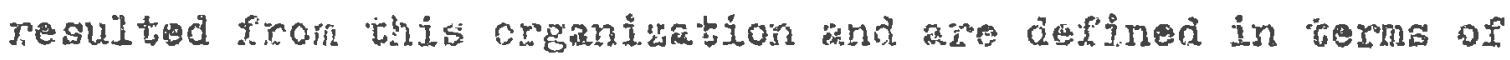
the organjus proparadness to forti speoific relationships botwear stimuli Solignan and Hager'

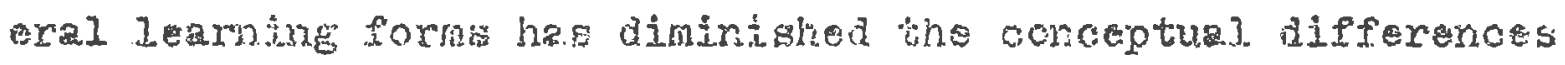
In leaming hald by traditional bohavioristo and ethologigt:o. One Iow ot laming degcribed by Seligman and Hager



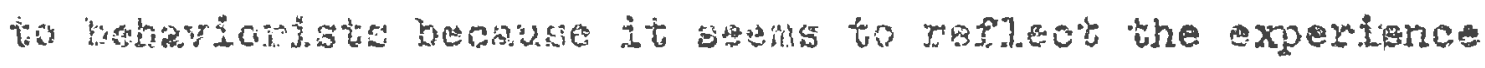

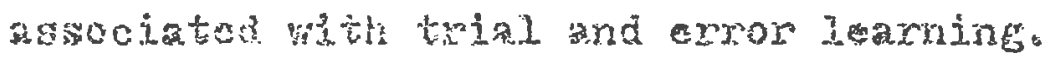

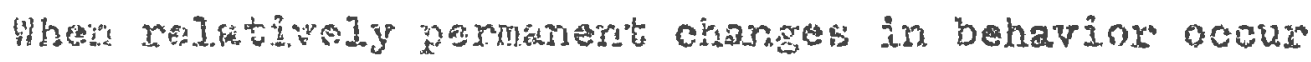

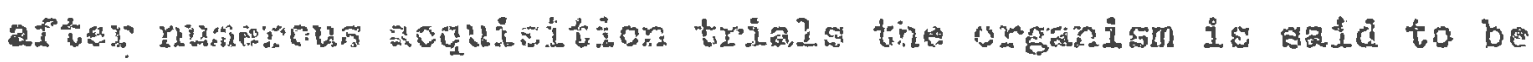

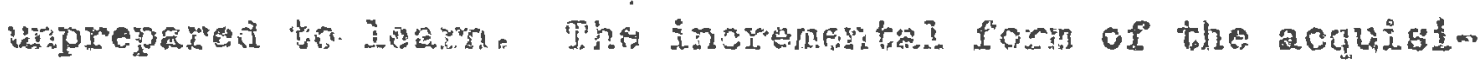

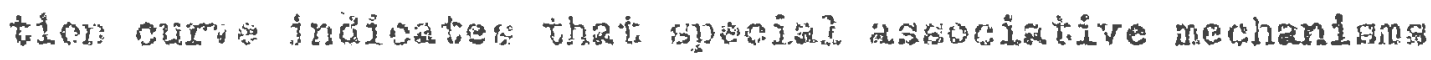




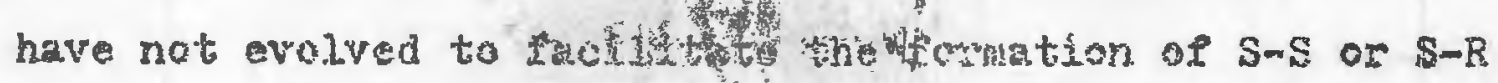
bonds. Paychologiets in the responss topograxhy that unprepared leaming studies are untainted by species specitia rosporse patterns. Hism torically, laboratory psychologists have been motivated to create leaming paradigms that are fxte from envicommental influences fust as the developmental specialist seek culture Iroe tests and Hoinghaus sought a verbai tagk independent of previous associations. When laboratory psycholegints were urexpectediy confronted with opeciss apscific responwe they were treated as a nuigance to be stitenuareo to the extont porsible.

The study of unprenared isaratng bat, in foct, eqtabilitaed numbrous law of leaming (K1mis, 1961). In fact, it has been such a usetul paradigm for investiggting the giradual fornation of associations that yuychologitis have come to thins of it ae the model for aequiming new and adatative modes of benavior. Howswer, ar growing body af paychologists belleve that unpreparea haws are ant exhaustive and da nat: describs on precict the pents subsumed urier prepared and contraprepared leaming oatogorfon (S世Iigman, I970, Bolles, 1970, Kadat ancè Roxin. $2971 \%$. 


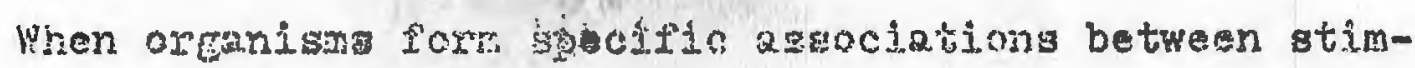

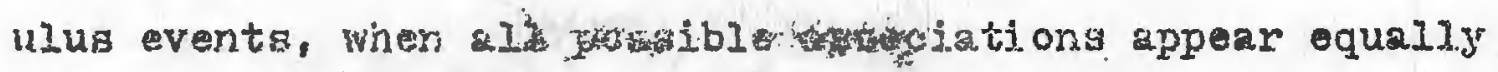
likely, the organiam is Baid to be displaying prepared leaming. Thet is, specific responses are learned and are eroked by only a subsei of all possible conditional gtimuli. Garcia et 23. (1961) kave illustxated this phenomenon by showing that rats \&ssoclate gastrointestiral illness with novel tagte cue only. extroceptive stimuli, both visurl and auditory, and fanifiar guetatory atimuli did not become associated with the indress even though these gtimuli were noce temporaliy' contiguous with the stomach malaise. It is interesting to note that Garcia used $x-r a d i a t i o n$ to induce the ilinews food items were not polgonous. Nonemthe-jegs, the rats astuoiated the malaise with the novel food and it only. on elbsequent opportunities when the rats were offered a cholce of the nerel food ox nere familiar food, both

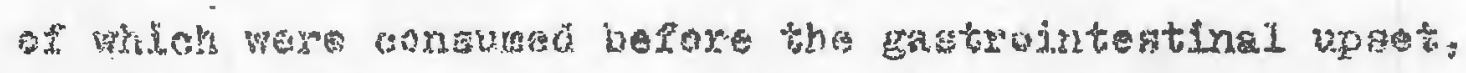
the ratis arolded the novel foed but not the nore faniliar roed.

Fris type of aroidance behavior, 2the other forms of preparednes Learning suoh as imprinting (Iorent, 1950),

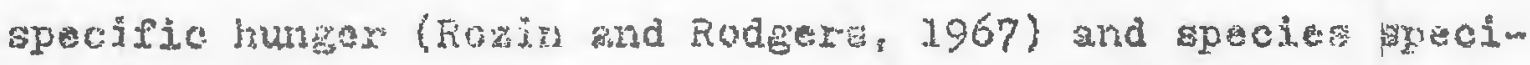


fic defensive reastion (bultes, 1970$)$, are thought to have

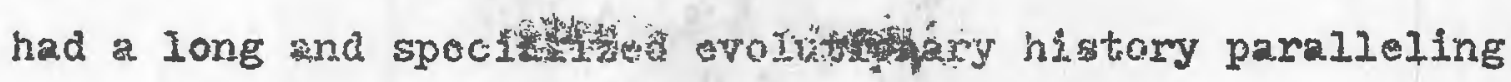
the development of specialized eensory and receptor organe. This paraliei development has been succinctiy illustrated by Lettin: Haturana, Pirts ard Mcrulleck (1959) who have described specializod colls ir the retira of the frog (Rana Piptens). Whese receptor cella ar: uriquely deaigned to dotuct convaz edgea of various insects only. Seligman (1970) reasons that gpectero response rendencies, like specialized seraory mechanisma, tend to enhance the sumpival of the apecies in the ratural environat.

Contraprepared leaming refers to Seligman's third discret category and is characterized by z very lengtiny acqui gition phast with lasming occurring oniy after an inordinate number of trials lat at sil. Conceptually, contrapreparednest rsalts when Ho experimenter atiempte to teach an axganism to make a response antagonistic to a prepared belsurior in situatione where iatural seleatior influence the respoase probability.

Braland ard Ereland (196i), repurtine or the "ndabehavior" of organiams, described their inability to tratu a raccoon to deposit two token in a contalner for foda 


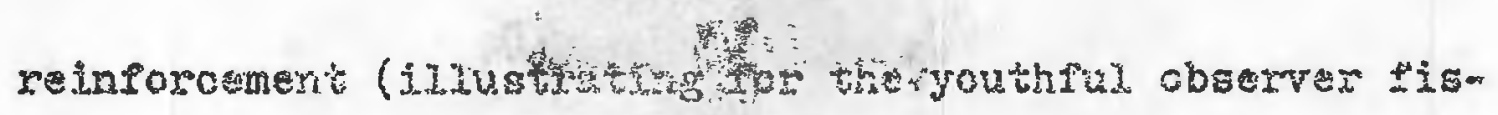

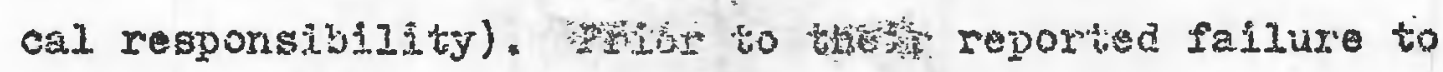
teach this response, the Brelends had no difeleulty conditioning the subject to deposit a single toren, thuz they returned to this earlitex phase to furtiner egtablish the simpier responas, Thay reported, however, that overlearmIng the first regponse did not faclitute the acquisition of the second two-tokes phase. Tra raccoon porsigtad in his misbeharior samjngly oblivious to the concept or positive transter. The Brolands reasonted that the pattem of perservativs binglors exhibited by the recooon, ocheidting of preconsurutary responses geciric to its species was so prepared that in the presenes of the considerable otimulus excitation producad by the two food-related torens, the prepared response bas unavoliabiy enttion,

In an analogous fachson, phobso humane treated by inm



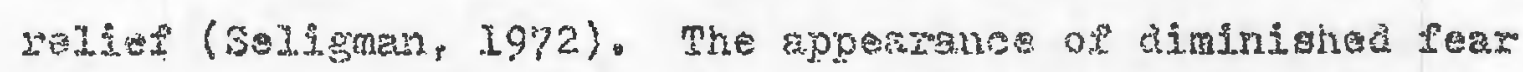
of the imagral phobis objectr(s) may occur because cogni-

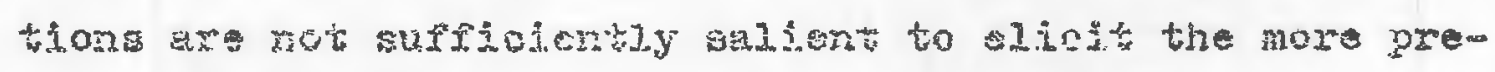
perentroinge response. The rato that cltents appear

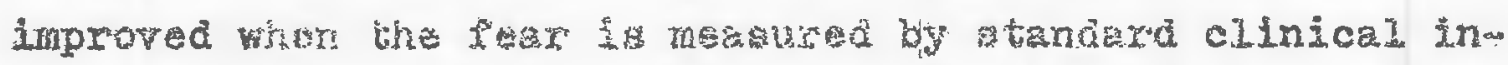




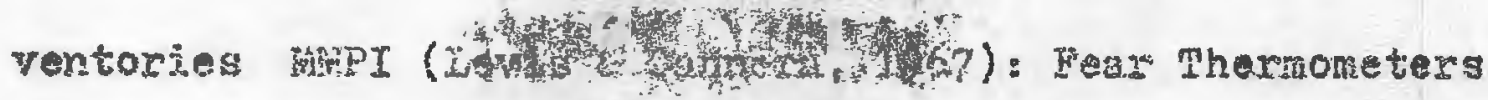

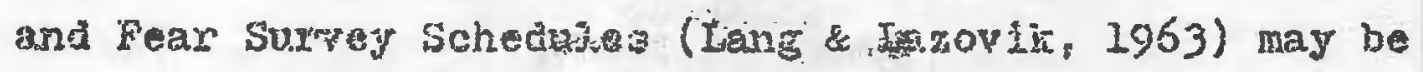
misleading. The client's verbal roboxt is discrepant with the results based on thase infartorises (Lang \& Lazovik. 1963, Lang, 1968, Millex \& Nawa, 1969). Verbal reports reflect the client"s real experiences with the phobic-relatod conditiorod stimuli. The discrepancy suggests thet when tho cues aro luaginal the client is able to make an unprepared or exua a ecntraprepared resporse anc remain in the presence of the far Inducing cognitiona. However, when the phobio gubjet it confronted with the real phobic object a propared remone appears inditande. The oritical factor may be the extent to which the cliont ie stimulated by the different par inducing cues.

Recent andyges of prepared leaxning undersoore the chncision arsived at by the Brelands"...that the behavior of axy gposios cknnot bo adequatein understood, predicted or controlisd without wrowlenge of its irstinctive pateme

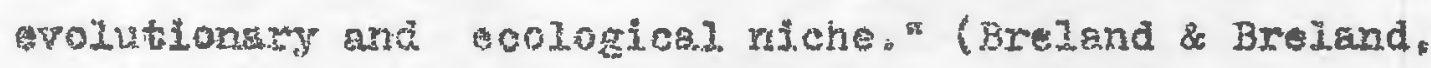
1961, p. 608). It is no loners appropriate to conclude

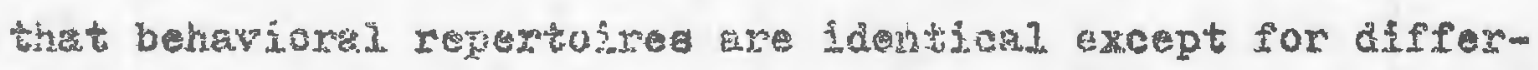
wees In the manter irs which organians contact and act upon 
their environment. This latter contention espoused by Skinner, one of the foremost. spokesien dition, [Skinner in Koch (ed.), 1959] and others who share his view of ethological influences on learning grant only "...that hormones, genetic determinants...and the like are ...determinants of parameter values only." Estes in Koch (ed.). 1959].

The remainder of this introduction will more fully develop the recent body of evidence reflecting on the significance of prepared Iearning, the factors that have been hypothesized to account for this phenomenon and will examine tho ethological-learning and general process learming position to determine if those leaming forms vary in significant ways or merely parametricalijy.

\section{Place Versus Taste Cues}

Since the original paver by Gavcla etal. (1961), there has been an increasing interest in the imaming ethological model. Garcia and Koeliing (1967) invsstigating tise acquisition of taste aversion found that gistatory stimuli (1 gm/. liter saccharine in water)paired with x-radiztion or Iitu-

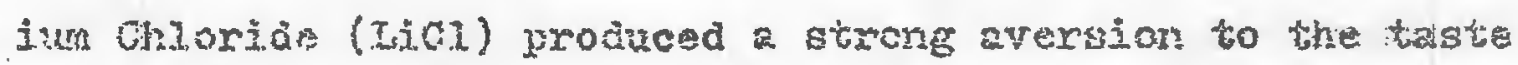
of the jaccharine, a rovel food for the mats. Ho avaxaton 
to a unique set of place che


"bright-noisy" water. When, upon vated an electrio circuit, an incaridegeent lamp (five watts) flashod and a clicking relay was repeatedily closed. These potential CS: did not berone avexgyve ingpite of the fact that $x$-radiation and IICl are powerful iliress inducing agents. Rats ghocked whis drinking "bright-noisy" watersaccharine solutions sidbequentiy aroided "bright-nolsy" drinkometers but not the gustatory simulu, the gacoharine, delivered in the absence of the sudiovisul cues. SubsequentIy, Revusiry \& Gared.t (1970) repörted data that appearg to control for backward condjtioning. Employing $x$-radiation as the UCS, zaccharire wa presented to rats four to oix hours after imradiation with no resulting arersion to the sacohaxine. An averbion was establiated when the rats woxe permitted to axini saccharine for the fivgt tims within tro hourg of the jrradistion.

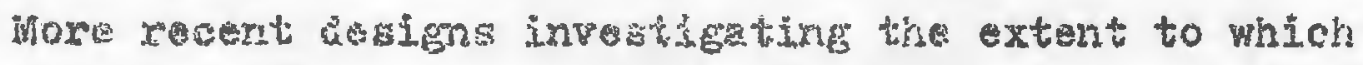

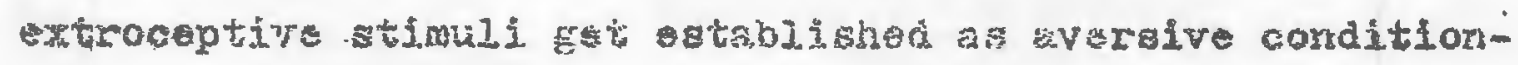
ed atiovil have produced reaulo that ass inconsistent with thoso roported by Garcla and Kcolling (196?). Henggeler 


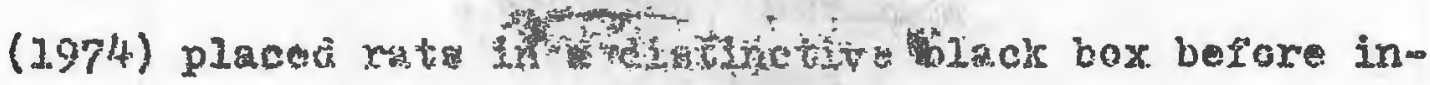
jecting the rats with Liti. On trials not reinforced with IJCI injections the rats were placed in a trantucent plastic box. During the tant phase the subjectis showed an increased latency to enter the black box and a decreased latency to leavo the tranglucent, safe box. Those results were consistert over several trials. Bravemin (1974) using guinea pigs found that subjects acquired an aversion to the coler of sojutions if the original colorsd solutions were followed by LiCl. Howeyer, the recovery from the condition. ed aversion is fastoy if color io the only cue associated with the Iicl. When baste is the aversive conditioned gtima ulus, recorery is more gradual indicating that taste 19 a more salient due. Bravenan suggests that it is not unusual to find that extroceptivemviaual oues become effective aversive cues for guinea plga. These urgainams are nore deperdont arion visual cues to secure thair rood than are mate. To controi for the pousibil1ty that the food coloxing was adding aublite gustatory cus to the solutions, Eravaman replicated the study ubing various colored tubes to deliver the food solution. The rasulta of thia control stuay were consiatert wh the orsthal sindinga. In perhapg the wost 


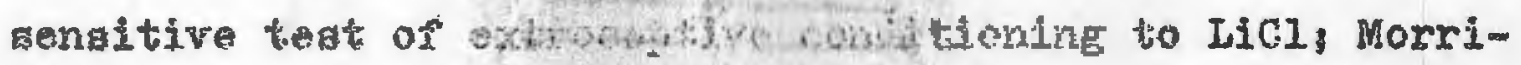

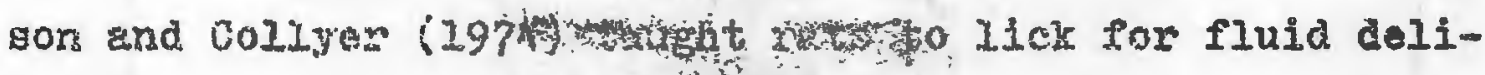
yered on 0 VI 3 gchedule. Dhring the conditioned aversion acquisition phas tho raigs licked distinctive tasting solution paixed with the onsot of the house jight. This was the only wizk the houge IIghts wes on. Sach of three acquisition irials was roinforeod with in injection of LiCI. When tested in tho prostanco of the houge light a significant suppreselon of the lisking regponse on the VI3 was ovident. The investigetion suggests that the atility to ostablish an extroceptive cut al an arergive conditionad otimulua may be due to the fact that there pere trree acguigition trials. Theoreticaday, the Iight was paired with tho IxCl od the second and thitrat trial by the mediation of tise distinctive tasting zolutlon. In the Garcia and Koellnig (1967) study only one asquistion trial was mployed thus the extrocep-

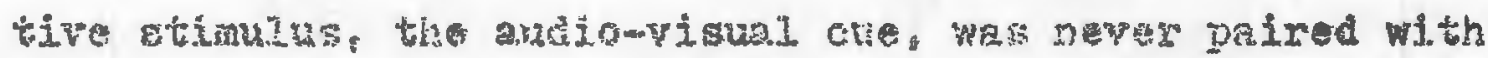

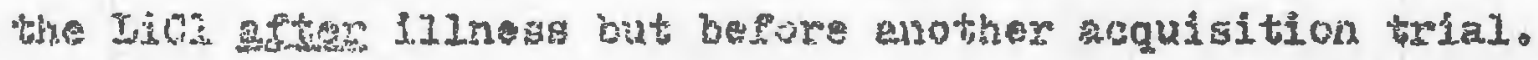
Perhapa hetar ore IIIness trial the rat would have been able

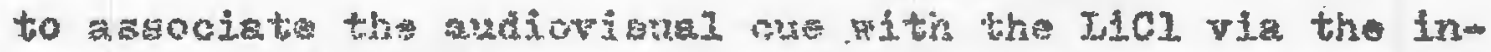

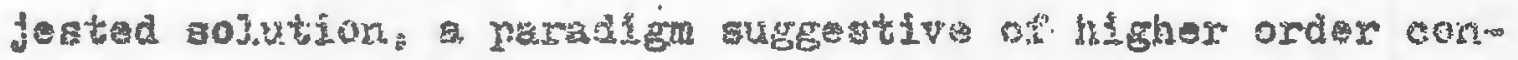
ditioning" In support of this explination, Morrison and 
Collyer found no supprissich of the haking response without a taste mediator. A,Iso, there was no suppression of licking to the light alone when the light-taste relationship was initially established in preconditioning trials followed by IiCl reinforcenent of the taste stimulus. Thus, there was no eviderce of sensory preconditioning. Although some evidence for extroceptive aversion conditioning is evident in the last three studies described here, it seerns that more input, neasured in trials is necessary to form this type aversion. An aversion to taste stimuli, howerer, ig apparent efter a single acquisition trial suggesting that taste aversion is a form of prepared learming while conditioned aversion to extroceptive, audio-visual cues, constitutes a forn of umprepared leaming. In this regard, Lorden, Kenfie]d and Braun (1970) have reported significant suppression of rasponding on \% VI 30 for water reinforcement In the presence of isoproponal vapor when rats had previousIy smelled, or sinelled and tasted isoproponal followed by illness. Jurder et al. reported that on the first day of testing of a sequence of inve test trials the rats that had smelled and tasted isopioponal followed by I.LCI svidenced a greater suppreasion of the licking response lix the presence of the 
rapor than rats having pretibudi only. There were no thepraces between the smell only and taste-smeIl groups on the second through rifth test days. Further, Smith and Balagotita (1969) fhave reported intragas-

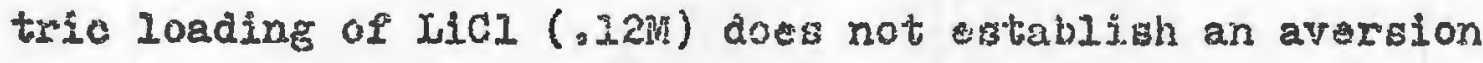
to IiCl or NaCI bcth of which are indistingujshable-salts. In the same investigation an averaion so IICI and NaCl was eqtablished after the rats drark a .12N golution of IiCl. Thus it appears that gustatory cues ar necessary to estabIIsh an avergion to novel eudutions and extroceptive stimuli and ars always moxe selient thar extrocaptive stimuli. However, not: all tasto stimuli are oqually galient. Kalat and Rozin (1970) have ahow that rato poisoned following the injestion of two norel solutiona associste poisoning more with une solution than the otner. Casin hydrolysate wa always more aalient (i.e. beckme more avergive) than sucrose, NaCl of vanjila when casjn hydrolyate was paired with one of the other solutious prist to the Iicl injecm tion. The averion was inore equally alstributed between the two solutions, however, whan gain hodrolysate was the socond of the two selutions consunes by the rats. Parenthetically, ralat and Rowin nowor there is no direct re- 


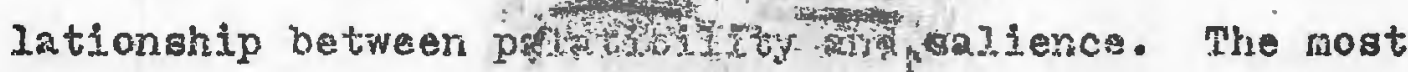
galient solution, casin fydrolysgte, is the least preferred solution by control rats but sucrose, the second most sali-

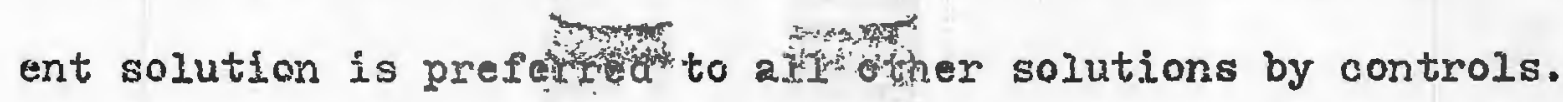

Three Hypotheses to Account for Condjtioned Taste Aversion

The body of eridence discussed "above identifies two factors that distinguish unprepared learning results from moxo recent findings bageci on prepared learning studies. First, investigator of prepared Ieaming phenomena including Garcia and Kcelling (1967) and nuwerous others (Revusky \& Beara: 1967; Kalat \& Rozin, 1970; Seligman, 1970 ; Revusky \& Garcia, 1970) have provided considerabie evidence from studies of specific humgers and learned taste averslona to show that all stimuli are not equally associable. Secondly, Smith and Foll (1967) and Revuaky (1968) have establighed delay of reinforcement gradients of six and eight hours respectively and CS-US intervals of $30 \mathrm{~min}$. to 120 min. are typical.

These results are in sharp contrast to those clerived from the higtorically inore traditional response measures - that characterize ungrepared learning (e.g. eyelid, pupilid.m Iy: heartrate and GSR conditioning), Whe results from thest 
leaming procedures, taken as a whole, consigtently provide evidence that all gtimuili are equally associable, assuming temporal contiguity [Eavov, 1928; Egtes in Koch (ed.), 1959]. Furthermore, close temporal contiguity in the order of seconds in thought to be nacessary to establlsh classical conditioning. Indeed maximur aseociations require that the period separating the CS and US be measured in fractions of

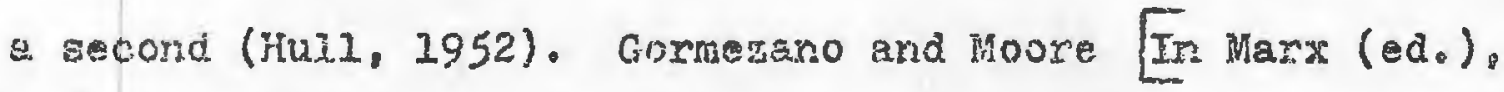
1969 report maximum alasaical defongive conditioning with ISI of 0.25 to $0.50 \mathrm{sec}$, and ximble (196I) summarizing the resulta from numerous gtudies of a variety of rewonge systems reports that $0.50 \mathrm{aEc}$ is a frequent ISI value for maximur conditioning. White and schlosierg (1952) also report 500 msec. as the optimal IsI for classical conditioning of GSR in hunans. Although the ISI range varies depending ans the response system being conditioned, classical conditioning with an ISI of less than 250 msec. sans rase and was found to ba too short for whits and Schlosberg (19y2). Notteman, Schoonfeld and Bersi (1952) were able so oftabligh some heartrat acnditionirg with $7000 \mathrm{msec}$. Isi which seams to approach the unper limit for CSm ss separation. Youne (1958) unable to establish a pupillary 
dilation response witt 1 委

The obvious differacice in JSI range for prepared and unprepared learning suggeste that the parameters which were thought to apply to all forms of classical conditioning need to reevaluated in light of successrul prepared leaming results employing ISI of one hour or nore. For some investigntors a revvaluetion of parametric value is not sufficient. Kalkt and Rozin [In Sejigman \& Hager (ed.), 1972 argue that the range of TSI for condin tioned taste aversion together with the specificity of CS conditionability warrents a more cognitive interpretation of the conditioning.

Three hypotheses have been suggested to account for the fact that conditioned taste aversion is characterized by gpecificity of associations and the lack of stimulus contiguity. Two of these hypotheses, aftertaste and interference are not new and have beon discussad in other contexts. Both theories are consistent with the view that prepared learring car be desoribed by the general process laws of learning except for the observed paranetric valuas. Leamed safety, the third hypothesis, has been more recentIy iormulated $2 s$ an alternative to the aftertaste and inter- 


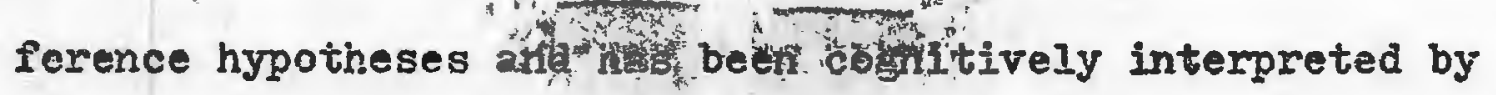
some investigators.

\section{Aftertaste Hypothesis}

The simplest explanation to account for taste aversion conditioning with long delays of reinforcement is to suggest that zome aftertaste of the novel solution is present when the subject becomes ill. If, in fact, this could be demonstrated, further discussion about gradients of delayed reinforcement would be mute and stimulus contiguity would be demonstrated. The data resulting from severai critical tests controlling for aftertaste do not support this hypothesis, however. Rozin and Kalat (1971) insist, that any aftertaste explanation of delayed learning must involve some unidentified "blood factor" or taste trace in the mouth. The former mechanism is highly speculative and there is only orse study in the literature that is of any relevance to it, Hunt, Carroll and Kimeldorf (1965) joined pairs of rate by vascular anastomosis. These parabiont rats, having a comnon circulatory system were then differentially treated to estabIish the extent to which humoral factors influence the acm quisition of a conditioned tasto aversion for the second of the joined pairs. One 2 to of a joined pair was pernitted 
access to saccharine feljowing an exposure to $x$-radiation. This rat always beadital and acharine aversion. The second rat of the pair also drank saccharine but was shielded from the $x$-radiation. The shielded rats that had consumed the saccharine but had not been irradiated exhibited a strong aversion to the saccharine too. Parabiont pairs consisting of a rat that received saccharine and $x-$ radiation, and a second rat that was shielded and drank unilavored water behaved differently. An aversion to saccharine was obvious for the saccharine-x-radiated rat but the water-shielded rat did no scquire an aversion. These results support the predictions of Hunt et 2l. that humoral factors influence the acquisition of a conditioned taste aversion. It appears that some metabolic change took place in the $x$-radiated rat which because of the comnon circulatory system affected the shielcied subject and produced an aversion to saccharine if the shielded gubject had also been exposed to saccharine prior to the malaise. These regults, although intriguing, io not clarify the significance of peripheral aftertaste because the study is piocedurally esoteric and. nay be unique to those instances where x-radiation is used as the US. Furthermoro, as Hunt ot al. report, the speci- 


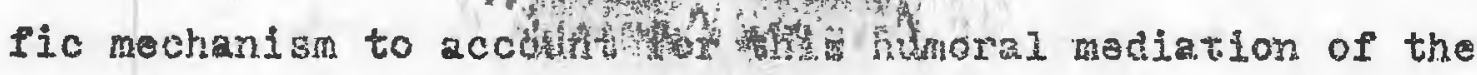

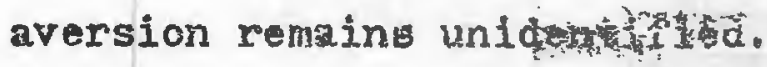

With the exception of the Kunt et al. investigation, researchers interested in the phripherad aftertaste explanam tion of delayed leaming nave comentrated their efforts on controiling for a specitic trace of the sulution which gerves as the CS. Revusky and Beuarf (1967) in a study 1Ilustrating the speciricity of conditioned taste aversion to the more novel of two gutatory cueg have by counterbalancing for che order also controlled for aftertaste. For nome subjects a familian foor $\left(C_{1}\right)$ wa foliowed by a bovel food $\left(\mathrm{CS}_{2}\right)$ before the LICI preantation. The CS order was rom versed for other aujects. The primary effect of this manipulation was the establishment of an avergion to the novel substance irrespective of CS order. The fact that the aversion waz specific to the novel solution when it preceeded the familiar solution wokens the argument that an aftertaste of the novel solution served to bridge the one hour ISI. If an aftertate romained, it would bo the taste of the familiar solution.

Further reasts reilecting usupportably on the aftertaste explanation have been reported by Garcia, Green and 


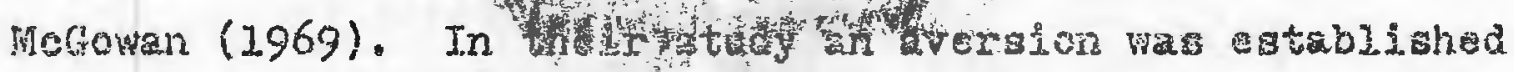

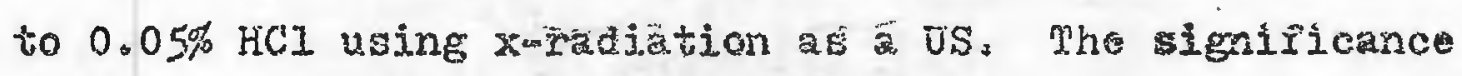
of these results aminates from the fact that the concentra tion ox HCl uझed by Greia t at is negligible compared to the concentration of this acid found in the stomach of the rats. of aqual aignificance ax the resuits reportid by Nachran (1970) indicating that an aversion could be eatablished to $43^{\circ} \mathrm{C}$ water when it was pared with apomorm phind. Water delivered at room temperature and not reinforced did not becone aversive. These results were replicated with cold water paired with the US with the same resulta. It appears thet the tamperature of water can serve as an effective C. for taste arergion conditioning and rats can discriminate betwen this CS and roor tomperature water that is not rinforcec. Since the potential CS's were both tap weter it is difficult to understand how a diferential trate cue associated with the hot (cold) water could arve as a taste-cue mediator. Some teroprature-tasta interaction mut oocur, however, alnes a weplication of this ax periment. using distilled water did not produce differental resuts for the hotod (cola) wher verous the rosm temperRture water. Plnally, in contradiction to the aftertate 
hypothesis, Rozin (1969) estulished an aversion to only one of two specific atsol to the concentration that was followed by LiCl.

Interference Hypothesis. Another mechanism that has strong historical roots in psychology to account for forgetting S-S or S-R events is interference (Kimble, 1961). For the phenomenon of conditioned taste aversion, however, the task is to account for the ability of some organisms, here the rat, to establish and maintain ISI's of up to eight hours (Revusky, 1968). Revusky and Garcia (1970) propose that the maximum CS-US interval depends not on time per se. but on the number of interferring stimuli that are present between the CS-US presentations. Since in taste aversion learning the range of potenicial taste stimuli that could intervene between the CS and US is restricted and generally non-exixtent the subjects tend to associate the US or its effect with the only gustatory stimuius available, the novel solution (CS) even though the interstimulus interval is measured in hours. This theory is very attractive because it proposes 2 general principle, interference, to account for the differences between taste aversion Iearning and other forms of unprepared leaming. 
However, as parsimonious as appear, the results of several critical studies indicate that the lack of interferring stimuli cannot alone account for the rats ability to associate stomach malaise with a novel solution. Kalat ard Rozin (1971) have reported that the coneumption of two or three novel solutions during a 30 minute interstimulus interval between sucrose consumption and poisoning does not eliminate the sucrose aversion. Thus, interrerence defined as the number of interpolated stimuli between the CS and US does not significantly attenuate the effect" of the acquired avergion. Other investigations reIlecting on the interference interpretation will be discussed undef the next heading.

Learned Safety hyothesig of kcquired Taste Avergion. Wachman and Jones (1974) and others have proposed a learned safety hypothesis to account for the conditioned taste aversion whenomenon. They suggegt that when a rat injesta \& nontoxio noval substance it gradually learns in the ensuing hourg that the substance is safe. This explanation would acconat. for tha limited amourt of novel solutions sonsured on the firet exposure trial (noophobia), the increased amount son- 
sumed on the second and subsequent trials when the subjects are not poisoned and the novel food is followed by poison.

In series of experiments testing the efficacy of the learned safety hypothesis, Nachman and Jones (1974) first made rats mildiy ill by injecting them with IiCl four hours after drinking saccharine. The long delay of reinforcement attenuated the degree of the illness. Two days later the subjects were given a two minute exposure to saccharine and at the end of one of four intervals; $4,30,1.20$ or $480 \mathrm{~min}-$ utes, a 10-minute reexposure to the saccharine. The amount of saccharino consumed in the ten minute test increased as the period between the 2-minute and 10-minute reexposure increased suggesting that the rats were learning that the saccharine was now safe. Four control groups were run using the same time paraneters to control for water deprivation as an alternative explanation for theise results. No significant difference in the amount consumed was found for the 430- 120- and 480-minute groups when y:ater replaced saccharine.

In a second experiment, four croups of rats were given two drgosures to saccharine. The interval between the first 
and second session wagnith $4,30,120$ and 480 minutes for

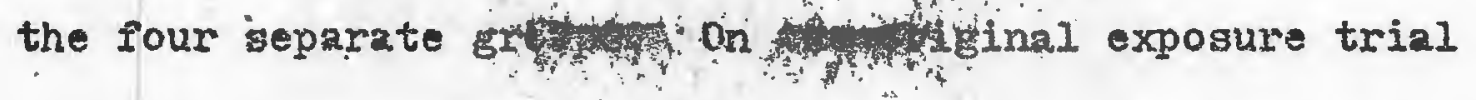
the rats exhibited the typical neophobic avoidance of the novel solution and drenir only small quantities of the saccharine. The amount of sacchaxine consumed on the second exposure was, howevor, different foy the four groups. As in the original experiment in this series, the longer the interval between the original exposure and the reexposure to saccharine the more Pluid ingested. A third experiment in this serieg was essentially a replication of Experiment II except that. six preexposures vere auministered, No direct effect of the varjous delays was noted in this instance assumedly because scme asymptote of leamed safety had been achieved by the sixth exposure, These rata were subsequentIy injected with LiCl st 4, 15, 30,60, 120 or 480 minutes after the sixth saccharine exposure and for the 120 - 240 and 480-ginute groups no avergion was noted. The degree of Fvarsion for the subjects in the 4-15-30 and 60-rainute Eroups was greatly reauced corpared to Nachman's data for subjects mot having received ropeated nonreinforced proexposures io gecishrine guggesting that learned safety attenuated the subsequent effect of the poisoning. However, 
the fact that thero is some fitet for the groups having

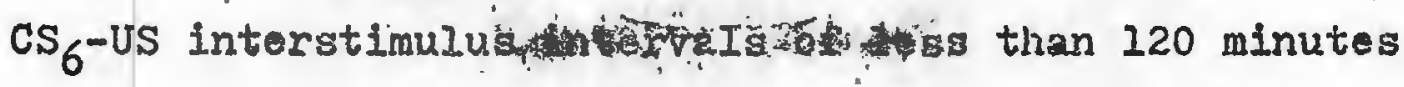
compared to the $120-240$ and $480-$ minute groups indicatea a trace decay effect. One might conclude that two mechaniæms, trace decay and learned saiety, are necessary to account for the acquired taste aversion phenomenon established with delayed reinforcement.

In a direct test of learned safety versus passive trace decay, Kalat and Rozin (1973) reported that one preexposure to a novel substance attenuated the subsequent conditioned tagte aversion 2 much as three or seven preexposures. Also, one preexposure 21 days before poisoning was about as effective as a single preexposure the day before a. subgequent reinforced trial. These results do not appear to enhance the passive trace decay explanation. However, they are not consistent with the results reported by Nachman and Jones $(1974)$

In another experiment in this geries, a group of rats woro permitted access to the novel solution (CS) at 3.5 and 0.5 hours before poisoning. Another group of rats received only a single exposure to the novel solution 0.5 houra before poisoning. The rata in the former group devel.- 


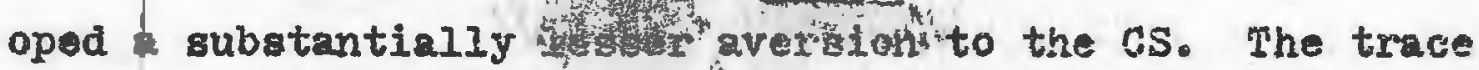
decay, theory predicts ax equal arersion fox both groupg while learned safety proponenta predict, as the resulta indicatp. a lesser avertrafifor thes 5-0.5-hour group because the latter group has four hours to learn that the novel food substance is safe.

Finally, in a study directed to the same end. Domjan (1972) infused $8 \mathrm{ml}$ of $0.2 \%$ saccharine into the mouth of rata via oral cannulae. Three groups wers infused at different flow rates; $0.6,1.2$ or $2.9 \mathrm{~m} / \mathrm{minute}$ resulting in a total saccharine contact time of $13.3,6.7$ or 2.8 minutes respectively before being poisoned. The two groups having recelved the two slower infusion rates and thus more exposure time to the CS exhibited a weaker aversion to the sascharine. These results corroborate those of Kalat and Rozin (1973) and support the contention that some unidentified mechanism actively monitors the subsequent gastric effect resulting from the injestion of novel roods. This mechanism appears to function as long as a trace, probably neural, remains active. Phis hypothesized noura]. trace appears to remin active for somating in the order of 8 hours (Reviakyr. 1968) but can be extendea if the subject is anesthe- 
sized following the presentation of the CS (Rozin \& Ree, 1972). The trace can hom liminated by cortical spread of depression procedures (Davis \& Bures, 1972) which is consistent with the hypothesis that the CS trace is neuroloGical and located in the central as opposed to the peripheral nervous system. Whether this mechanism is cognitive or more "primitive" [Kalat \& Rozin in Selignan \& Hager, 1972 ] remains unanswered. 


\section{Statement of the Problem}

Thus far investiftoris have shown that the laws of general process (unprepared) learning do not adequately describe the acquisition phase of prepared learning. The results of numerous investigations, many of which have been detailed here, consistently indicate that prepared responses are acquired in a single trial and are specific to a subset of all potentially associable stimuli. Somewhat surprisingly, little is known about the extinction phase to prepared learning. What little information is available seems to suggest that the extinction of an acquired taste aversion, in contrast to acquieition, corresponds more closely to the extinction of unprepared responses (Garcia, Erwin \& Koelling, 1956). With the exception of the Garcia et al. (1966) data and a report by Grote and Erown (1973) indicating that deprivation expedites the extinction of a conditioned taste averaion, no systematic invegtigation of extinction procedures appears in the literature.

To further determine the variables that affect prepared leaming this study sought to describe the extent to which dearned taste aversions were subject to three ox- 
tinction procedures. The thice pacedures were (I) the repeated pregentation of the CS whout reinforcement (US), (2) a no treatment condition which served 28 a retention control, and (3) the repeated presentation of the US alone. The predictiong of the effectiveness of these procedures were based on the conclusions, viewed collectively. from the unprepared leaming iiterature. Extinction of classically conditioned unprepared reaponses occurs when the CS is repeatedly presented without the US. This fact is true for all species of organisms that have been conditioned irrespective of the response system involved (Razran, 1939). Although little is known about the elimination of prepared behaviors established by classical conditioning, the avaliable evidence does suggerst that repeated CS presentations will extinguish the prepared response (Garcia et. al., 1966, Grote \& Brown, 1973). These invegtigations were not studies of extinction per se. but did provide some evidence that reflect on this process. Since. no further information was avajiabie and bocause these stuaies are consistent with the unprepared learning data relative to extinction a consavative prediction based on the systenatic elimination of a prepared avoidance reaponse 
was appropriate. 'Thus, the inst hypothesis was: the same

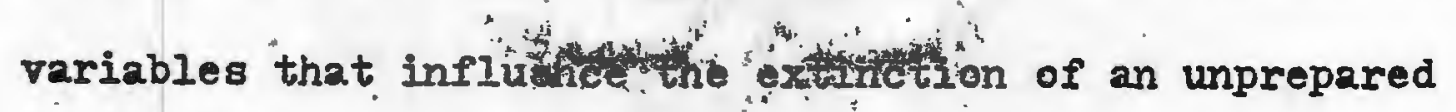
avoidance. response would apply specifically to the extinction of a prepared avoldance response. The conclusions resulting from this hypothesis were (i) Extinction involving the repeated presentation of the CS in the absence of the US w111 be superior to the other extinction technique used in this study. (2) The more trials of this variety administered, the more extinction that will occur. stated in terms of the dependent measure this means that the rats adminis tered 10 forced exposures to the CS will consume more saccharine than those rats administered five extinction trials to the CS. Those rats given one forced CS trial will evidence the least recovery of the subjects treated in this manner when tested after extinction.

Kalat and Rozin (1971) have concluded that leamed taste aversions are adaptive responses having significant survival value. Inferences from this corclusion can be outlined in a series of statements: (1) the consummatory behavior of the rat ie prinarily. influenced by Eustatory cues. (2) stomach malaise probably results irom the consumption of poisoned "food". since the eating of many foods has occurred before, 
without poisoning. (3) "uture prosdabe of this "food" is essential and dependentors the ratability to recognize this substance by its gustatory quality.

It was logical to conclude, applying these statements of adaptability, that aversions to gustatory cues associated with illness are acute rather than chronic. This conclusion has merit from a natural selection stendpoint i.e. it limits the size of the category of poison "food" and would result in future sampling of previously polsoning "food": If this speculation has merit, one would expect to see $a$ reduction in the avoidance of the CS simply as a function of time. Thus, the second hypothesis wass not only do the variables of unprepared extinction apply to the elimInation of 2 conditioned taste aversion but adaptive mechanisms based on natural selection augrnent the likelihood of extinction in the absence of any treatment. The predictions based on this logic weres (1) "treacnent" invelving neither the presentation of the CS nor the US will eventually dirninigh the conditioned taste aversion, (2) the longer the retention interval between the last poisoning and the test presentation of the CS, the weaker the aversion to the CS. Thus, a retnetion interval of 20 days will result in more exw 
4

tinction of the avoidance response than one of 10 days. A

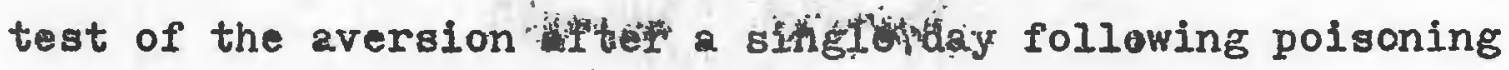
will not be an effective treatment procedure.

Kalat and Rozin in Seligman and Hager (1972) have suggested that conditioned taste aversions may be a form of cognitive leaming. They reason that the rat actively ascribes it's illness to the novel CS. This interpretation is in contrast to a more "primitive" (non-cognitive) form of leaming and has provoked considerable discussion among researchers who subscribe to the learned gafety interpretation of condltioned taste avergion. Although Kalat and Rozin have not provided data that supports a cognitive explanation for the taste aversion phenomenon, 2 test of it's explanatory efficacy was included in this study. This test involved the repeated injection of poison (liCl) after conditioning. If the rat has cugnitions and actively attributes it's malaise to the novel saccharine solution then repeated non-contingent illness should elicit other cognitions inconsistent with the original ones. There cognitions should Pacilitate extinction when the CS is subsequently presented without the US. Relative to the prediotions of outcome it was inconsistent with the original hypothesis to 
conclude that repeated Iicl injections would facilitate extinction. The original hypothesis stated-that the princi(1)

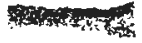

ples of unprepared learning apply to the situation described in this study. In the unprepared literature one finds that repeated US presentations subsequent to conditioning sensitize the subjects i.e. maintain the aversion when the CS is subsequently presented (Kimble, Mann \& Dufort, 1955). ThersIore, the predictions relative to tinis were: (I) Iicl injections following saccharine-Licl pairings will maintain the conditioned taste avorsion, and (2) the sensitization will be most evident for those subjects receiving 10 non-contin.. gent injections. Sensitization will also be evident for the five-injection and single-injection groups.. 
METHOD

Subjects

The subjects were 72 experlinentally naive male rats about 65-days old obtalned from the Charles River Breoding Laboratory. Subjects wero randomiy assigned to control or experimental Eroups.

\section{Apparatus}

The experiment was conducted in stardard $20 \mathrm{~cm}$. square wire mesh housing units. The solutions pers presented in 100 cc. drinking tubes (Kimble \#44875) constructed to prevent dxippage and accurate to $0.25 \mathrm{cc}$. Interperitoneal injections wore administered with a 5.cco glass syringe.

\section{Procedure}

Twelvo subjects were mu in erch of six replications. Each Eroup of 12 sakg ras subdiviod into four groups of three gubjects ouch and zun in one of the axperimental conditions. Placonent within each of these groups was randos as was the cholce of gxporinental groups for each replica- 
tion. The description of the proserue is a general one that doss not describe each of these repilcation but does describe the differential treatment of each of the twelve suberoups (See Table 2).

Training triala. For sive days prior to treining abjects Hore handled and adapted to a 22wour-water-deprivation gohedile. On day six and seven subjects vere placed in oxperimental cages and permited one hour acease to water. made available in two drining tubes mouted on elther corm nex of the rear wall of tha caee. This procedure fmiliarince subjecta with the prooegs of drinking erom the trbes.

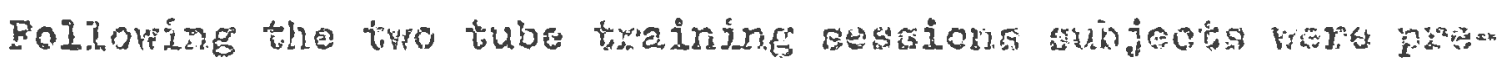

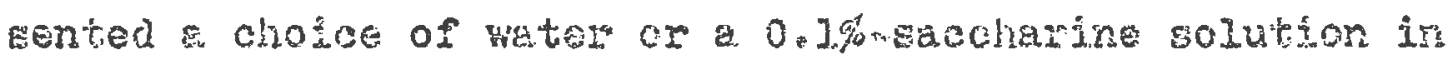
Gach of the drinking fubs. Subjects hat access to the solution cor one half hour and were then removed to their home cages. No food or water was avallabic in the hone cages at this tione.

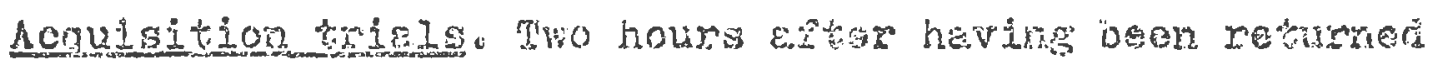
to thalr homs cages tince grouns of 18 subjecto wero in-

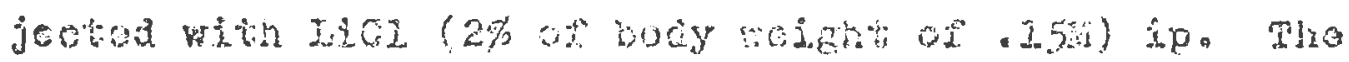

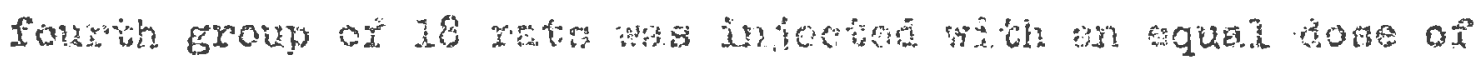

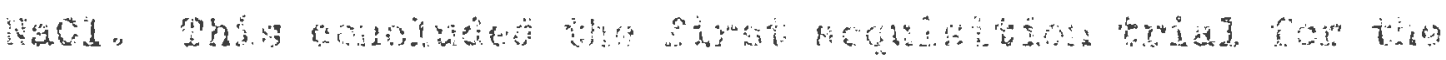


TABLE 1

Design of the Acquisition and Extinction Phases for the Experimental and Control Groups

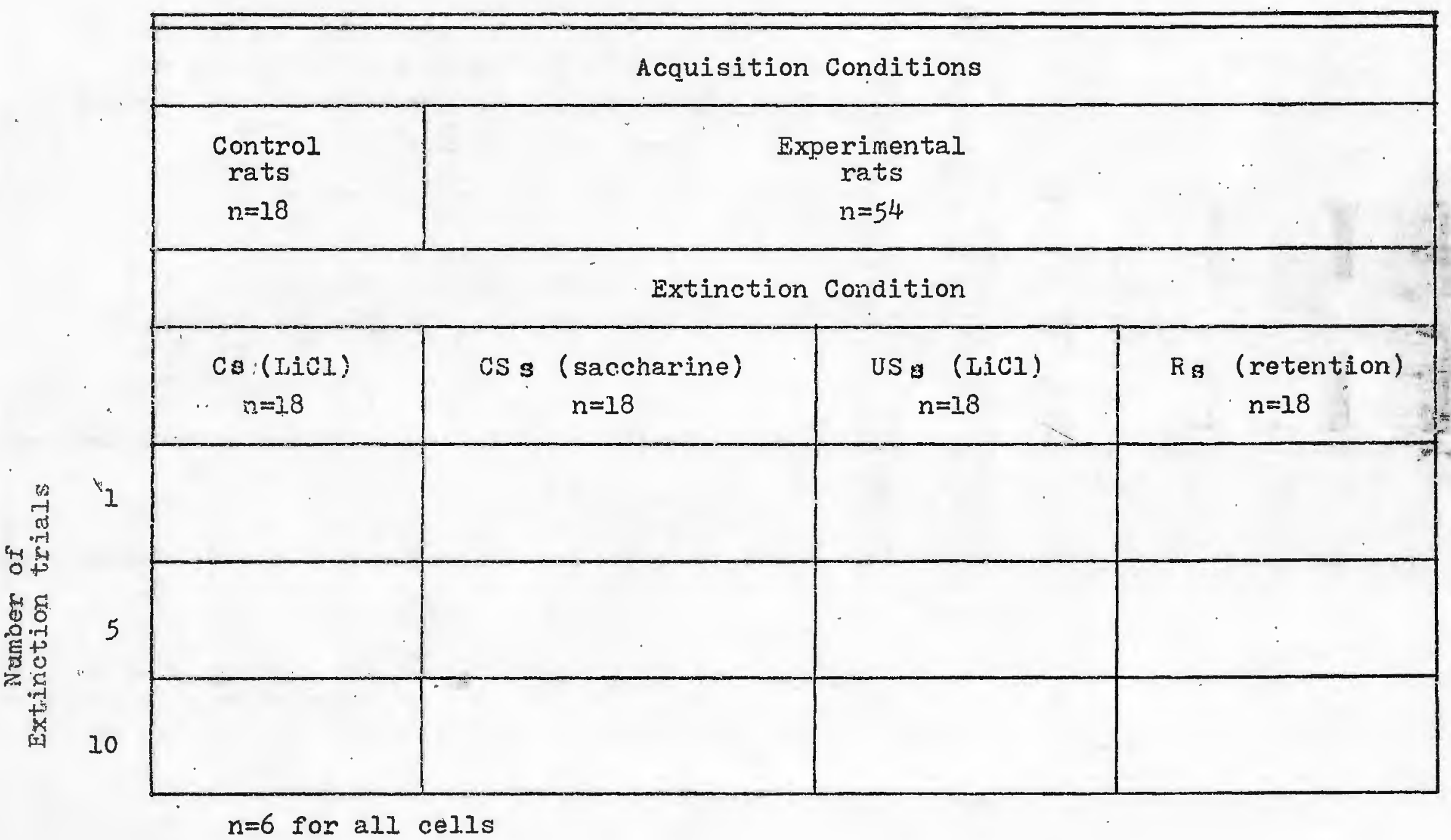


Iour groups.

After the injections all subjects wero given access to water for two hours in their home cages. Food was also avallable in the form of gtandard Táb blocks. The food remained available until the next tube-drinking session. The removal of the water after two hours resulted in a 19.5 hour deprivation schedule for the next and all subsequent sessions. The next session, on the following day, constituted a check for prolonged 1llness; All subjects were placod in the experimental cages and were allowed to drink from the tubes for one half hour. Both tubes were filled with water only. Forty-aight hours after the Iirst session a second acquisition trial was run with the same deprivation level and delay of reinforcement (LICl or NaCl) maintained. The water tube and saccharine tube positions were reversed, however. A final acquisition trial occurred 48 hours after the second with an illness sheck session (water in both tubes) on the interpolated day between session two and three. This concluded the acouired aversion phase of the investigation. The dependent measure during this phase was the amount of eaccherine consumed on each of the three acquj.s1tion days. The whount of water consumed or the in- 
terpolated days was also reterded.

Extinction trials. The 54 subjects which received saccharine followed by LiCl were assigned to one of three extinction conditions. Eighteen subjects were subdivided into three subgroups of six subjects each that received either 1, 5 or 10 forced exposures to saccharine only. Forced exposure was accomplished by filling both drinking tubes with Baccharine. The extinction phase began for the tinree subgroups on the day following the last acquisition trial. For those subjects receiving more than one forced exposure to the saccharine, extinction sessions occurred every other day. On interpolated days subjects were given water in both tubes. The specific extinction procedure was as folLows; after 19.5 hours of water deprivation the three groups of rats to be administered the forced exposure to saccharine were placed in the experimental cages for one hall hour. Since only saccinerine available this procedur exposed subjects to the conditioned stimulus (CS) in the ebsence of the unconditiened stimulus (US), the LiCl. The three saccharine forced exposuro subgroups sro hereafter reforxed to as $\mathrm{CS}_{1} \cdot \mathrm{CS}_{5}$ ard $\mathrm{CS}_{10}$. At the concluzion of the half kour gession the CS $\mathrm{g}$ wero given accoss to food and 


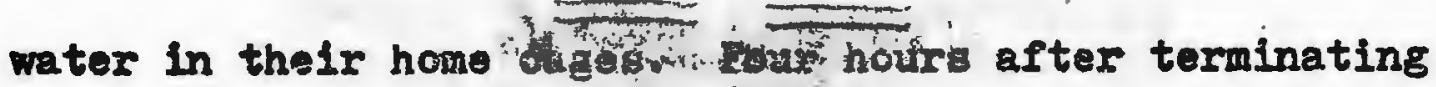
the extinction session the home-cage water bottles were remored. The food remained arailable ad lib. until the beginning of the next session. This process continued for the $\mathrm{CS}_{5}$ and $\mathrm{CS}_{10}$ groups for 10 and 20 days respectively. On the interpolated days, CS sujjects were given water in both tubes in the experimental cages. The experimental and home cage procedure, howerer, remained invariant.

1 second group of 18 rats was subdivided into three subgroups of six rats each and received 1, 5 or 10 non-contingent injections of LiCl. Since IICl served as the unconditioned stinulus, these three groups axe hereafter referred to as US $\mathrm{US}_{5}$ and $\mathrm{US}_{10}$. The infections, $2 \%$ of body weight of .15M IICl ip, were administered every other day to the US ${ }_{5}$ and US 10 subgroups for 10 and 20 days respective1y. "The procedure on the interpolated days was the same procedure adainiatered to the CS subjects.

The remaining $18 \mathrm{rats}$ of the 54 that received saccharine and IICI in acquiaition wore not given any treatment during the extinction phase of the study. Since no treatment followed by a test of the arersion etrength to anccharine constitutes a tos: of the retention of the saccharinem 


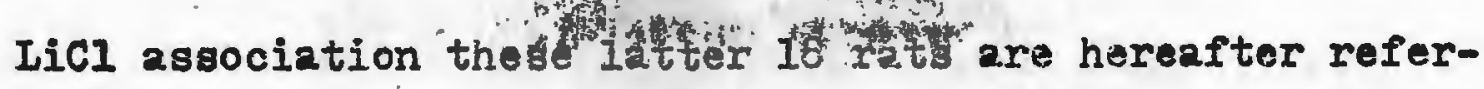
red to $28 \mathrm{Rs}$. Three subgroups of $\mathrm{Rs}$ were formed; $R_{1}$ which wrs tested one day aiter acquisition and $R_{5}$ and $R_{10}$ which were tested after 10 and 20 days respectively. While the rats in the CS and US conditions were receiving their extinction sessions the Rs were merely handled for several minutes. On interpol.ated, non-extinction, days the $R_{5}$ and $R_{10}$ groups were treated in the same manner as the CS and US groups.

The 18 subjects that had been injected with $\mathrm{NaCl}$ on each of the acquisition trials served as dual-purpose controls. Firsi, all 18 served as conaitioning-acquisition controls. Since $\mathrm{NaCl}$ does not produce gastric upset in rats no aversion to saccharine (conditioning) should result. Thus, the amount of saccharine consumed should increase from trial to trial during acquisition. Prior to extinction the 18 control subjects, hereafter referred to. as Cis were subdivided in three equal subgroups, $C_{1}, C_{5}$ and $\mathrm{C}_{10} \cdot \mathrm{C}_{1}$ received one non-contingent injection of IICl while the latter two subgroups received 5 and 10 injections respectively over 10 and 20 days respectively. on the interpolated nor-extinction days the control rats 
were given access to water in both drinking tubes in the experimental cages atcereribed the groups above. Thus in the extinction phase the $\mathrm{C}^{\circ} \mathrm{s}$ served a second purpose as sensitization controls for the effect of 11Iness per. se. Testing trials. The final phase of this study constituted a tert of the effectiveness of the three extinction procedures. At the conclusion of their respective extinction phase each of the twelve subgroups (See Table 1) was returnod to the experimental apparatus and reexposed to the saccharine-water choice procedure. Water was always available in one tube while the other tube contained the $0.1 \%$ saccharine solution. Counterbalancing for tube position was continued throughout the test phase. There were seven test seszions of one half hour duration on seven successive days. Subjects were never administered LICI during the test phase. In all cases subjects were 19.5 hours water deprived at the begiuning of a test session and were given access to food and water in their home cages two hours after the conclusion of each teat session. The water remained avallable for two hours only while the food remained accessable ad lib. until the next test trial.

Two dependent measurea vere of interest in the test of 
extinction effectiveness; (i) the amount of saccharine consumed on the first tepty and the recovery sequence as measured by saccharine consumption over the entire test phase.

Despite some heterogeneity of variance in some of the 12 subgroups the major analyses were done using analyses of avriance. The ANOVA was used because heterogeneity of variance is not a serious problem when other conditions are met. Boneau (1960) describes these conditions as does the Lindquist (1953) presentation of the Norton study (1951). In brief, if the sampling distributions have different variances or deviate from normality but are approximately symmetrical in shape, there will be little effect of heterogeneity on the F test. This conclusion is predicated on equal cell size. A perusal of the group distributions in this study indicated very litile skeweoness or departure from normality and all celi frequencies were equal. Relative to the multiple comparison test employed in this study, the Scheffe test, (1963) reports that it too is insensitive to departures from normality. 


\section{RESUITS}

\section{Acquigition of the Conditioned Taste Aversion}

Prior to analyzing the acquisition data the 54 experImental subjects were assigned to one of the three extinction conditions, CS, US or R. These 18 subjects per condition were further subdivided so that six subjects from ench condition would ultimately receive 1,5 or 10 extinction trials. This grouping resulted in the formation of nine subgroups. The 18 control rats were also subdivided into three groups of six subjects each (See Iable 1). Throughout the acquisition phase the nine experimental groups were treated identicilly. They were injected with IiCl after being exposed to saccharine. The three control subgroups were administered $\mathrm{FaCl}$ after thein saccharine exposure. The subgroups wore analyzed, after assignment to their respective extinction conditions, to lllustrate that prior to the extinction manipulation 21.1 experimental groups (and aII control groups) were equated in their dem 
gree of saccharine avergion.

The acquisition procedure entuiled the differential

treatment of the nine experimental groups relative to the three control groups. Alu. 72 subjects were given three half hour daily exposures to saccharine every other day. The experimental subjects were injected with LiCl two hours after the termination of each exposure trial. The control subjects, on the other hand, were injected with NaCl.

The prodiction was that the experimental subjects would acquire an aversion to the novel tagting substance, the saccharine, because of the IfCI inducer illnest. The controls, however, would not become ill and no saccharine aversion would regult.

Table 2 illustrateg the mean amount of saccharine consumed on each of the tinre acquisition trials for the control and oxperimental subjecte. The acquisition phase of Figureg i-7 visually illustrate these data. The figures cleariy indicate that the control aubjects increase their intake of gaccharine on each of the three acquisition triala. The experimentel groups markedly decrease their congusption of saccharine on the second acquisition trial with a near floor effect after the first Licl in- 


\section{TABIE 2}

Mean Amount of Saccharine Consumed (Cubic Centimeters) on Each of the Three Acquisition Trials

\begin{tabular}{|c|c|c|c|c|c|c|c|}
\hline Groups & $N$ & Ma & ${ }^{1} \mathrm{SD}$ & $\begin{array}{l}\text { Day } \\
\text { Mean }\end{array}$ & ${ }^{2} \mathrm{SD}$ & $\begin{array}{l}\text { Day } \\
\text { Mean }\end{array}$ & ${ }^{3} \mathrm{SD}$ \\
\hline Controls & 18 & 6.22 & 4.03 & 11.21 & 3.25 & 12.53 & 4.43 \\
\hline $\begin{array}{l}\text { Conditioned } \\
\text { Stimulus }\end{array}$ & 18 & 5.29 & 2.80 & 1.11 & 0.86 & 0.72 & 0.77 \\
\hline $\begin{array}{l}\text { Unconditioned } \\
\text { Stimulus }\end{array}$ & 18 & 5.74 & 3.67 & 1.07 & 0.85 & 0.56 & 0.36 \\
\hline Retention & 18 & $5 \cdot 35$ & 3.47 & 1.39 & 1.03 & 0.72 & 0.41 \\
\hline
\end{tabular}


Fig. I. Mean amount of saccharine conslued on each of the three acquisjtion trials and on each of the seven test trials for the control rato. 
MEAN SACCHARINE CONSUMED
$(C C)$

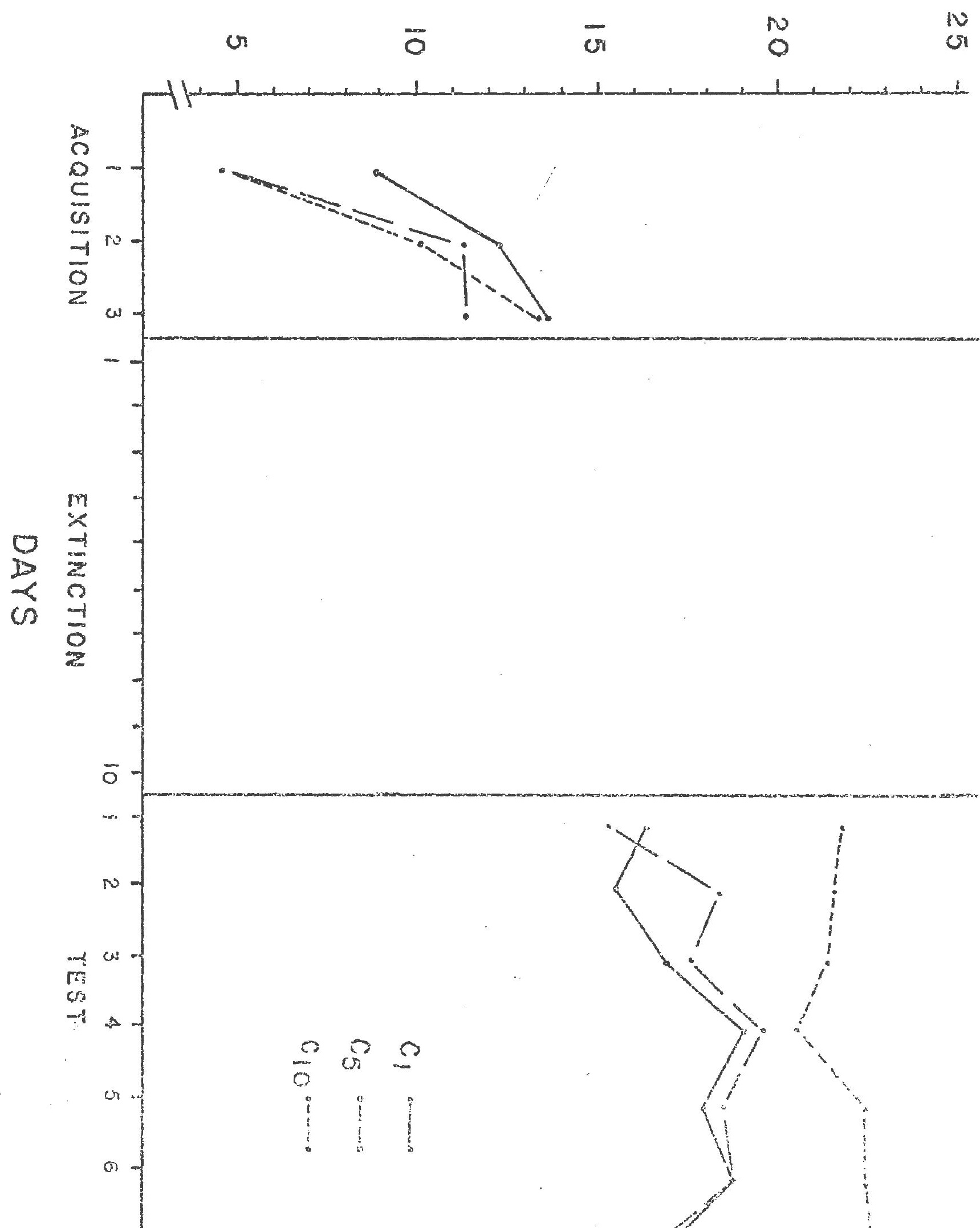


Fig. 2. Mean anount of saccharine corsumed on each of the three acquisition trials and on each of the seven test trials for the rats extinguished by the forced exposure to saccharine. 
MEAH SACCHARINE CONSUMED (c)




Fig. 3. Mean amount of saccharine consumed on each of the three acquisition trials and on each of the seven test trials for the rats extinguished with Jicl injections. 
53

$$
\begin{gathered}
\text { MEAN SACCHARINE CONSUMED } \\
\text { (CC) }
\end{gathered}
$$

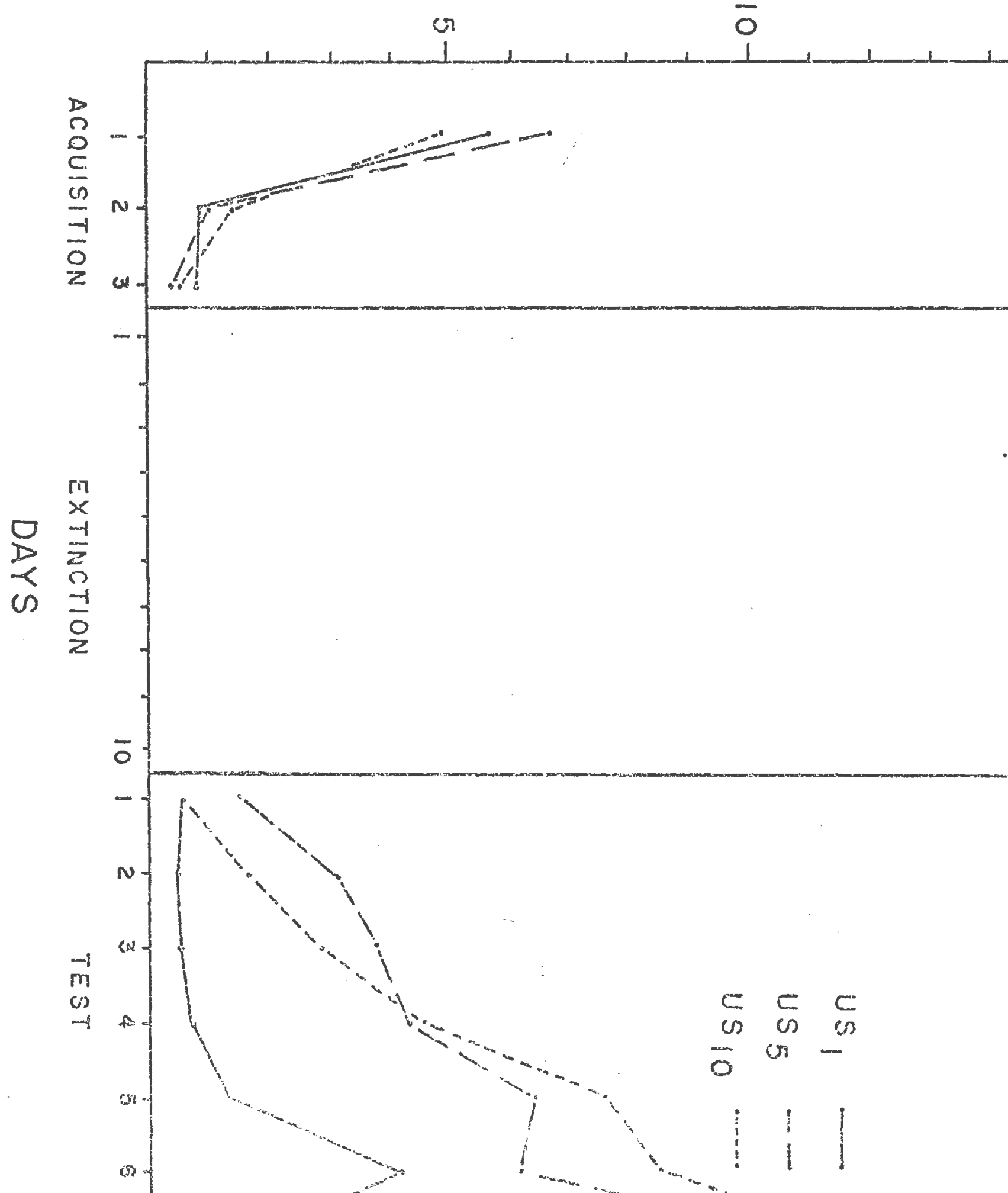


Fig. 4. Mean anount of saccharine consumed on each of the three acquisition trials and on each of the seven test trials for the jats in the retention extinction condition. 
MEAN SACCHARINE CONSUMED
(CC)

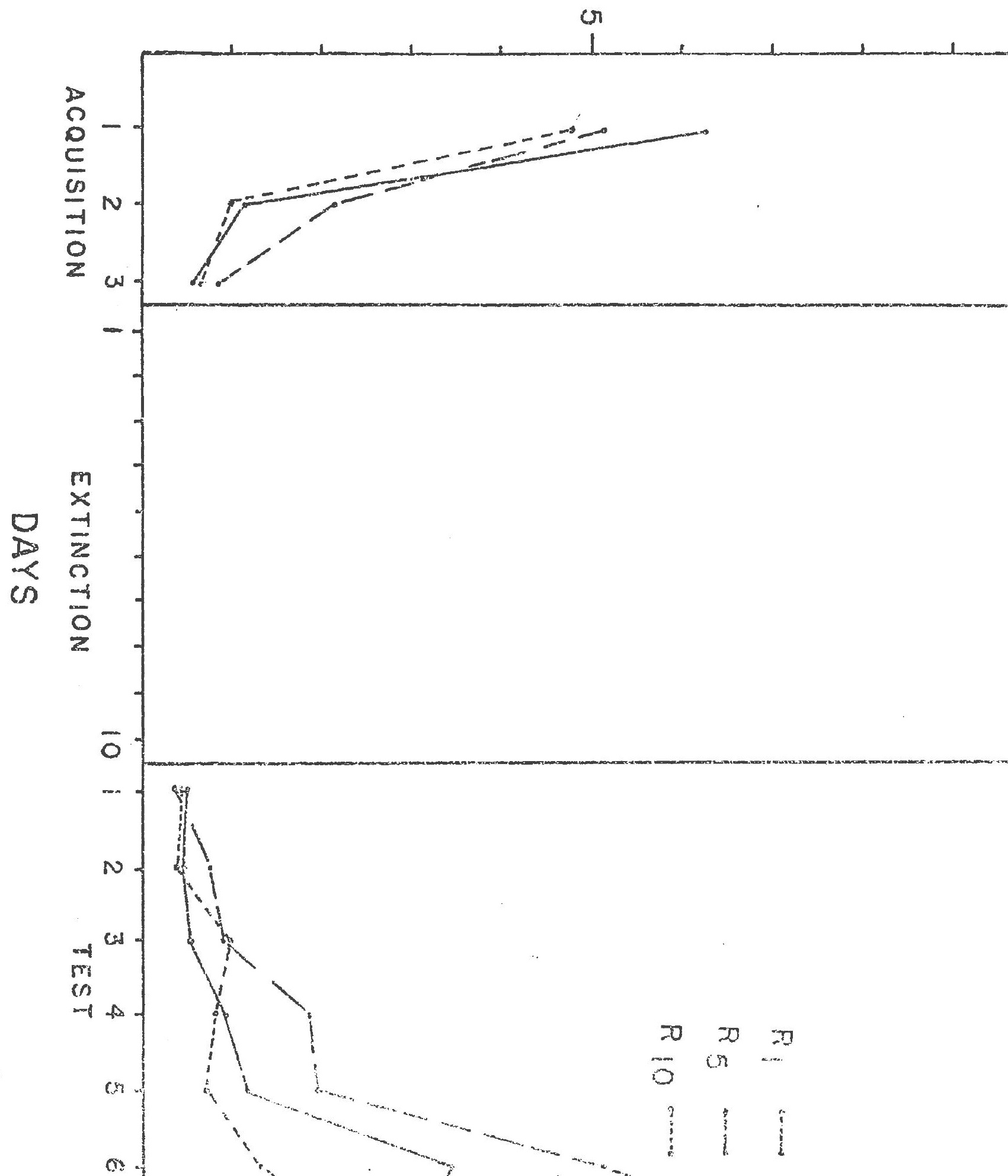


Pig. 5. Mean amount of saccirarine consumed on the three acguisition trials and the seven test trials fos a.11 groups having received one extinction trial. 
55

MEAN SACCHARINE CONSUMED (cc)

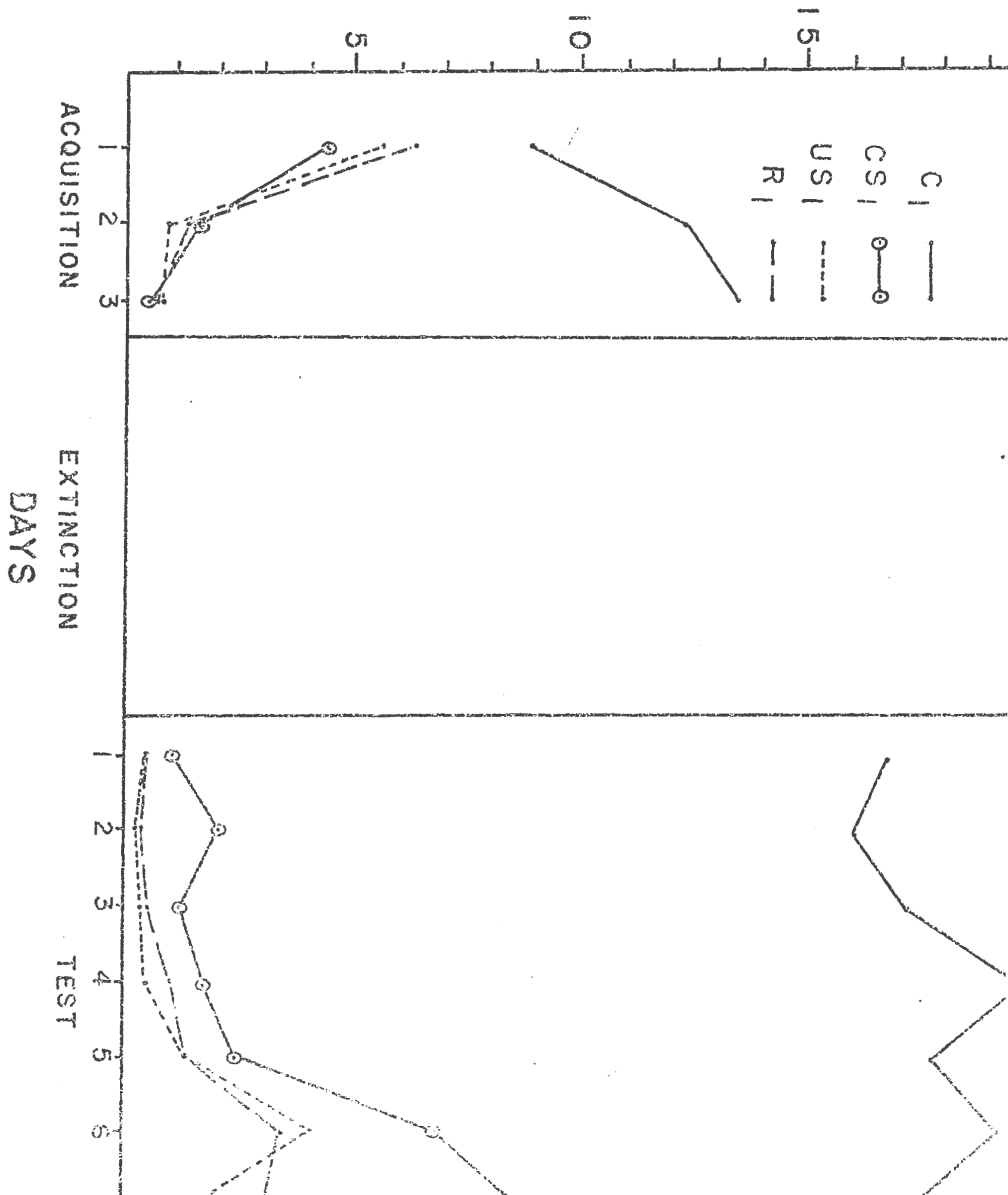


Fig. 6. Mean amount of saccharire consumed on the three acquisition trials and the seven test trials for all groups having received five extinction trials. 
MEAN

SACCHARINE

CONSUMED

(cc)

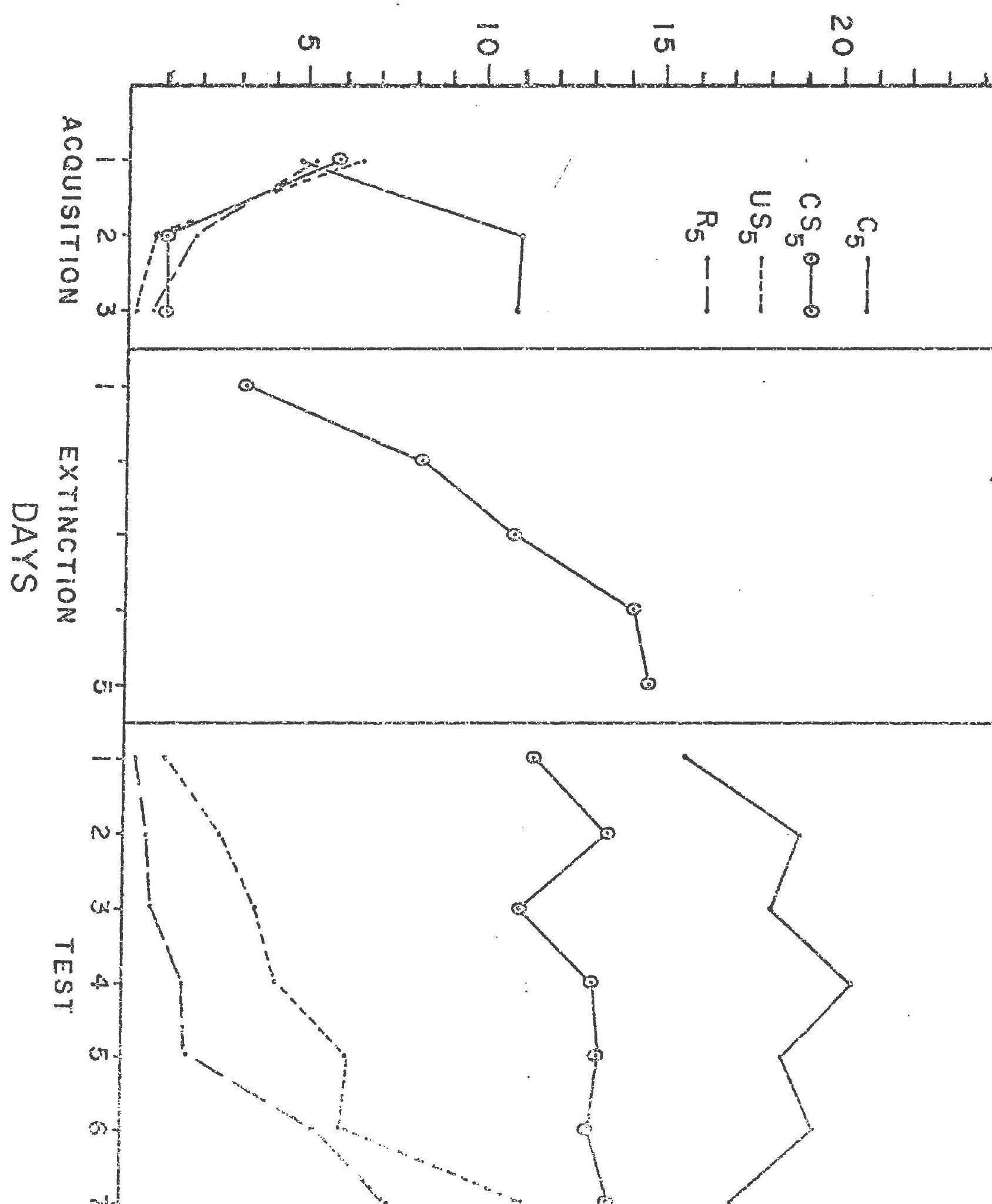


Fig. r. Mean amount of saccharine consumed on the three acquisition $[r \cdot \dot{i}$ s s and the scren test trials for all groups having recejved ten extinction trials. 
MEAN SACCHAFINE CONSUMED
(CC)

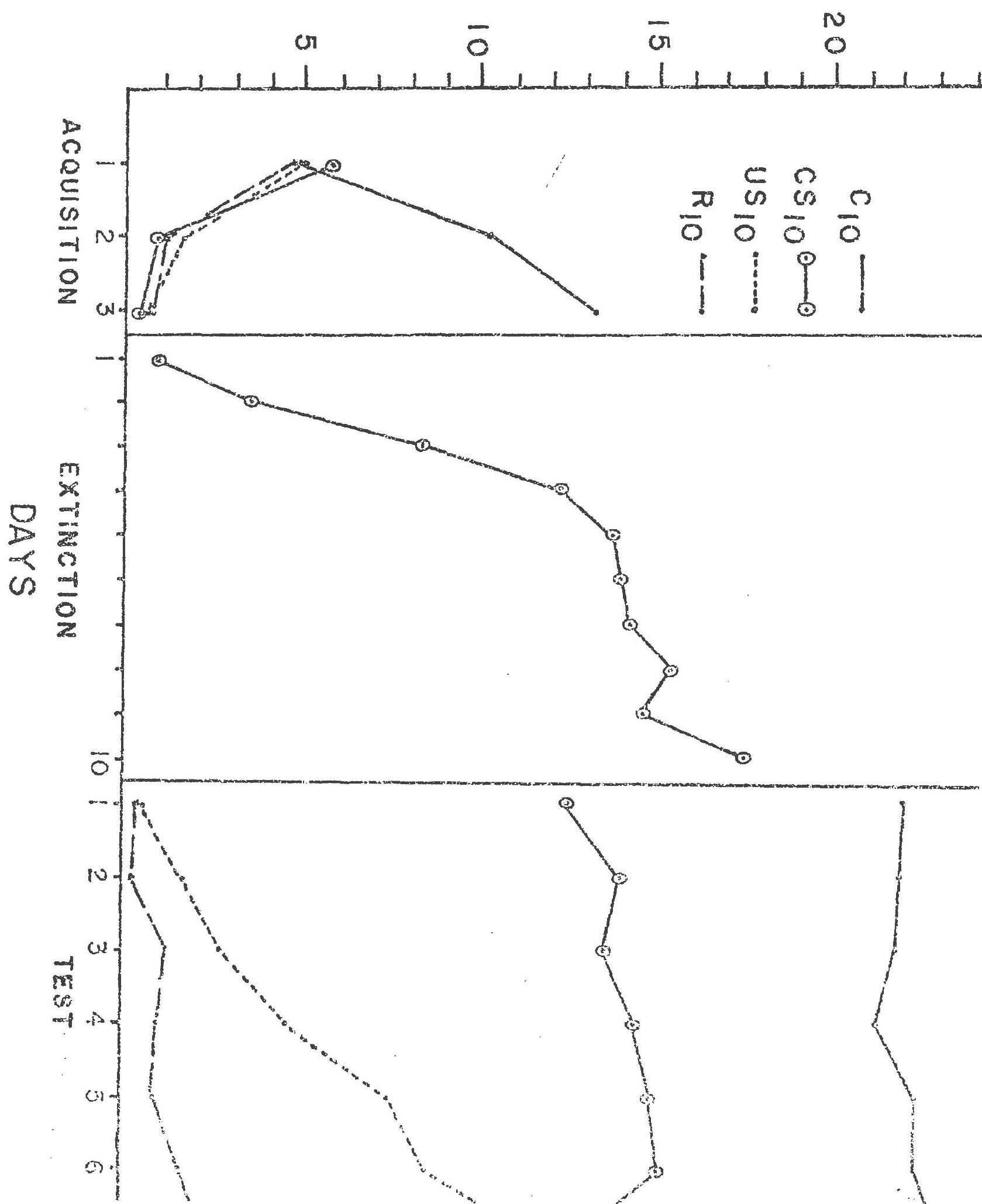


jection illustrated on the second acquisition trial relative to the third trial.

A three factor mixed design ANOVA, exinction condition by number of extinction trials by sessions (acquisition days), was used to determine the significant main effects and interactions. The source table for this analysis appears as Appendix A. This three way ANOVA with one repeated factor (sessions) indicated a significant extinction condition effect $(F=96.41, d f=3 / 60, P<.001)$. A Scheffe Multiple Comparison Test (Winer, 1971) was employed to determine the group differences. The scheffe test indicated that the Cs drank significantly more saccharine than the GSs, VSa or Rs $(F=18.51$, $d f=3 / 60, P<.001)$. It further indicated no differences between the CSs, USs or Rs. The ANOVA 2 lso indicated a significant sessions (acquisition days) effect and the sessions by extinction condition interaction 21 so was significant $(F=36.28, d f=2 / 120, P<.001$ and $F=32.58, d f=6 / 120, P<.001$ respectively.

The scherfe multiple comparison of the interaction data indicated that the controls and all the experimental groups were equated on the amount of saccharine consumed on the first acquisition day $(F=67.87, d f=11 / 120, p<, 001)$. 
Furthermore, the controls drank the same amount of saccharine on acquisition days two and three but more than they drank on the first exposure to saccharine. The controls drank significantly more saccharine than the CSs, USs and Rs on days two and three also. There was significantly more saccharine consumed by the CSs, USs and Rs on the original acquisition trial compared to trials two and three but no difference between any of these groups on the second and third acquisition trial. Apparently a single saccharineLiCl pairing is sufficient to produce 2 near maximum aversion to the saccharine. The means show in Table 2 clearly illusirate these results.

The Amount of Saccharine Consumed on the First Test Day

The effect of the extinction procedure was determined by recording the amount fo saccharine consumed on the first of the seven test trials. The preaictions were that the CSs would evidence the most recovery and no recovery would be indicated for the USs. Some effect of recovery was expected for the $R_{5}$ and $R_{10}$ groups. The extinction condition by number of extinction trials interaction showed that the CSs having received 5 or 10 extinction trials 
drank 29 much saccharine as $C_{1}$ and $C_{5}$ on the first test day and significantly tore than toutss and Rs which were equated on saccharine consumed. This indicates that $\mathrm{CS}_{5}$ and $\mathrm{CS}_{10}$ are nearly fully recovered as a result of forced exposure to the saccharine. $C_{1}$ is not different from the USs or Rs providing evidence that although the forced exposure to the saccharine is an effective extinction procedure, 2 single treatment in this manner is not sufficient. The data for the first test day on Tables 3-6 and Figures 1-7 graphically display these results. A two way ANOVA, factorial design, was employed to determine the effect of the extinction procedures and the number of extinction trials as well as the extinction condition by trials interaction. The source table for this analysis appears as Appendix $B$.

This two way ArOVA showed a significant extinction condition effect $(F=141.40, \mathrm{~d} f=3 / 60, P<.001)$. The scheffe test indicated that the Cs drank significantly more saccharine than the CSs, USs and Rs on the first test session (F= 8.28, $d f=3 / 60, P<.001)$

The number of extinction trials was al60 a significent iactor in therecovery from the acquired aversion to saccharine $(F=11.60, a f=2 / 60, E<.001)$. The Scherfe Test 


\section{TABLE 3}

Mean Amount of Saccharine Consumed (Cubic Centimeters) on Each of Seven Test Trials $(n=6)$ by the Control Groups

\begin{tabular}{|c|c|c|c|c|c|c|c|c|}
\hline Groups & & 1 & 2 & 3 & 4 & 5 & 6 & 7 \\
\hline \multirow{2}{*}{$\mathrm{C}_{1}$} & Mean & 16.83 & 15.96 & 17.08 & 19.88 & 17.86 & 19.21 & 17.25 \\
\hline & SD & 6.34 & 6.01 & .4 .43 & 4.34 & 5.10 & 5.55 & 5.04 \\
\hline \multirow{2}{*}{$C_{5}$} & Mean. & 15.25 & 18.79 & 18.04 & 20.08 & 18.50 & 19.00 & 16.86 \\
\hline & $S D$ & 6.13 & 5.24 & 4.84 & 3.01 & 2.15 & 2.65 & 3.20 \\
\hline \multirow{2}{*}{$\mathrm{c}_{10}$} & Mean & 22.04 & 21.96 & 21.88 & 21.29 & 22.58 & 22.58 & 23.13 \\
\hline & SD & 7.85 & 4.90 & $7 \cdot 58$ & 6.61 & 7.43 & $9 \cdot 34$ & 6.40 \\
\hline
\end{tabular}


Viean Amount of Saccharine Consumea (Cubic Centimeters) on Each of Seven Test Trials $(n=6)$ by the Saccharine-Only Groups

\begin{tabular}{|c|c|c|c|c|c|c|c|c|}
\hline Groups & & 1 & 2 & 3 & 4 & 5 & 6 & 7 \\
\hline \multirow{2}{*}{$c s_{1}$} & Mean & 0.92 & 1.96 & 1.17 & 1.71 & 2.54 & 6.83 & 8.86 \\
\hline & SD & 0.63 & 1.75 & 1.11 & 1.15 & $2 \cdot 38$ & 4.72 & 7.77 \\
\hline \multirow{3}{*}{$\mathrm{CS}_{5}$} & & & & & & & & 11 \\
\hline & Mean & 11.63 & 14.25 & $11 \cdot 33$ & 13.86 & 13.96 & 13.79 & 14.29 \\
\hline & $S D$ & 4.05 & 6.46 & 5.08 & 4.85 & 3.77 & 2.14 & 4.44 \\
\hline \multirow{2}{*}{$\operatorname{cs}_{10}$} & Mear & 12.54 & 13.96 & 13.50 & 14.25 & 14.75 & 14.86 & 12.42 \\
\hline & SD & 5.86 & 3.70 & 4.72 & 7.44 & 5.59 & 6.43 & 7.14 \\
\hline
\end{tabular}


Mean Amount of Saccharine Consumed (Cubic Centimeters) on

Each of Seven Test Trials $(n=6)$ by the LiCl-Only Groups

\begin{tabular}{|c|c|c|c|c|c|c|c|c|c|}
\hline Groups & & 1 & 2 & 3 & 4 & 5 & 6 & 7 & f \\
\hline \multirow{2}{*}{$\mathrm{US}_{1}$} & Mean & 0.54 & 0.38 & 0.46 & 0.58 & 1.25 & 4.04 & 1.42 & 1 \\
\hline & $S D$ & 0.37 & 0.21 & 0.68 & 0.30 & 1.86 & $2 \cdot 56$ & 1.48 & \\
\hline \multirow{2}{*}{$\mathrm{US}_{5}$} & Mean & 1.29 & 2.96 & 3.71 & 4.25 & 6.29 & 6.17 & $11 \cdot 38$ & $a$ \\
\hline & $\mathrm{SD}$ & 0.62 & 2.53 & 3.64 & 3.74 & 3.43 & 5.42 & 7.42 & \\
\hline \multirow{2}{*}{$\mathrm{US}_{10}$} & Mean & 0.50 & 1.50 & 2.75 & 4.54 & $7 \cdot 50$ & 8.54 & 11.96 & \\
\hline & SD & 0.45 & 0.91 & 2.19 & 4.29 & 6.97 & 8.85 & 9.36 & \\
\hline
\end{tabular}


TABIE 6

Niean Amount of Saccharine Consumed (Cubic Centimeters) on

Each of Seven Test Trials $(n=6)$ by the Retention Groups

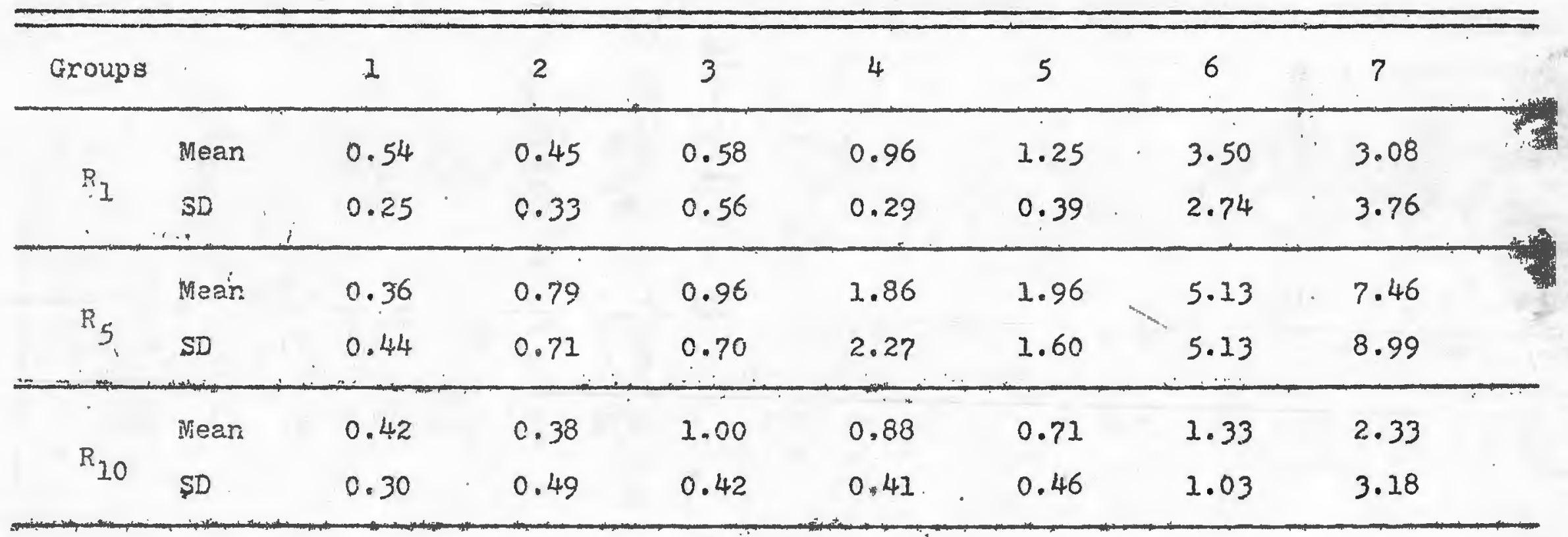


indicated that 10 extinction trials are superior to five extinction trials which are more effective than one extinction trial $(F=15.52, d f=2 / 60, P<.001)$. The significant interaction effect $(F=9.00, d f=6 / 60, P<.001)$ added clarity to these results. The Scheffe inultiple Comparison Test of the interaction effect showed that the $C_{s}$ having received 10 extinction (sensitization) trials drank more saccharine than any of the CSs regardless of the number of extinction trials. However, the CSs having received five or 10 extinction trials drank as much saccharine as the controls having received one or five sensitization trials. Finally, 211 of the $\mathrm{Cs}$ and the CSs having received five or 10 extinction trials drank significantly more than the USs or Rs irrespective of the number of extinction trials administered to the latter two groups $(F=36.75, \mathrm{~d} f=11 / 60, P<.001)$.

The Amount of Saccharine Consumed over the Entire Test Sequence

The effect of the extinction procedures were also examired over the entire seven day test sequence. The predictions were the same as those discussed under the previous heading. This procedure was employed for a specific 
purpose. It was reasonea that the effect of the extinction procedure may not be fudent fromatingle observation of the saccharine intake on one test day. The extinction procedure effect, it was thought, might interact with the saccharine presentation over the entire choice test phase. This result might occur for the Us: which were made repeatedly and non-contingently ill during extinction.

The effect of the extinction manipulation when measured over the entire test sequence shows that the CSs never fully recover and do not consume as much saccharine as the Cs. Clearj.y, however, forced exposure to the saccharine is the most effective extinction procedure for rats having acquired a conditioned taste aversion. Five forced exposures are as offective as 10 but a single forced exposure is ineffective. Although at the outset of the test phase the USs manifested as strong an aversion to the saccharine as the Rs. The recovery exhibited by $\mathrm{US}_{5}$ and $\mathrm{US}_{10}$ suggests that the repeated non-contingent iliness has a delayed effect which is potentiated by the choice procedure of the test phase. US ${ }_{5}$ and $U S_{10}$ consume much more arccharine than US $\mathrm{US}_{1}$ and all of the $\mathrm{F}_{\mathrm{s}}$ by the end oI the test 
sequence. Tables 3-6 and the test data of Figures 1-7 graphically display thesherifsitits

A three factor mixed design ANOVA, extinction procedure by number of extinction trials by sessions (test days), was employed to determine the effect of the extinction manipulations. The Source. Table for this analysis appears as Appendix C. This three way ANOVA indicated a significant extinction effect $F=122.67, d f=3 / 6, P<.001)$. A comparison of the extinction conditions by the Scheffe test showed that the Cs drank more saccharine than the CSs, USs or Rs over the consecutive seven day period. The CSs consumed significantly more than the USs or Rs $(F=18.51, d f=3 / 60, P<.001)$. There was also a significant $F$ statistic for the number of extinction trials effect $(F=18.06, d \hat{f}=2 / 60, F<.001)$. The Scheffe comparison of these three parameters indicated that overall the subjects that had 10 extinction trials consumed more sascharine than the subjects that were administered five extinction trials. Both of these groups drank more than the subjects having received a single extinction trial ( $F=12.34$, $d f=2 / 60, P<.001)$. The interaction of extinction conditions by trials was 27 so significant and of interest $(F=5.70$, d $f=$ $6 / 60 . P<.001)$. 


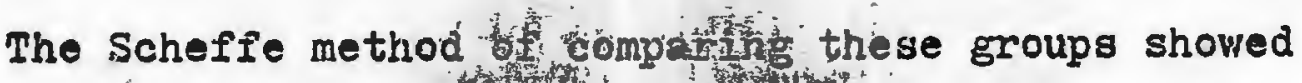
Hat.

that $C_{1}$ and $C_{5}$ were equated on the amount of saccharine consumed over the entire test phase. However, $C_{10}$ ärank a greater amount than either $C_{1}$ or $C_{5}$. Since none of these groups were made contingently ill during the acquisition phase 1.e. saccharine and IiCl were never paired, the increased $C_{10}$ intake may simply be a function of age and weight. The Cs irrespective of number of extinction trials consumed more saccharine than any of the Cs. These results indicate that the non-contingent IiCl injections administered to the Cs as a sensitization control for illness pers. se. confirm the necessity for saccharine-Licl pairing in order to establish an aversion to the saccharine. These results, furthermore, would seem to suggest that full recovery from conditioned aversion does not occur at least with the parameters employed in this investigation. Consistent with those findings described for the single test of recovery, $\mathrm{CS}_{10}$ consume no more saccharine than $\mathrm{CS}_{5}$ but significantly more than 211 other groups with the exception of the Cs noted above. Of particular interest is the fact that is 5 consumes as much saccharine as is 10 . and both consume significanțy more saccharine than $\mathrm{US}_{1}, \mathrm{CS}_{1}$ and all Rs. These 
rosults would tond to contirti on extinction procedure-test phase interaction. kepeated non-contingent injections of Licl followed by saccharine in a water-saccharine choice situation has a beneficial effect on recorery from the aversion. Finally, there are no differences between $R_{1}, R_{5}$ and $\mathrm{R}_{10}$ nor between these groups and $\mathrm{CS}_{1}$ or US $\mathrm{US}_{1}$. The ANOVA indicated a significant gessions (test days) affect $(F=25.00, d f=6 / 360, P<.001)$ which after further analysis using the Scheffe test showed an increase in saccharine consumption over the seven day test phase $(P=37.02$, $d f=6 / 360, P<.001)$. The sessions by extinction condition Interaction was also aignificant $(F=3.75, \mathrm{~d} f=18 / 360, \mathrm{P}<$ $5.001)$ but is not of particular interest because the minimal amount consumed by $\mathrm{CS}_{1}$ US $\mathrm{S}_{1}$ and $\mathrm{R}_{1}$ depresses the other CS's, US'S and R's to such an extent as to make a comparison of the experimental groupg meaningless. The sessions by trials interaction was not significant $(F=1.25, d f=12 / 360$, i.s.) but is of no interest to this investigation in any case. Finally there was a significant three way interection: gessions by extinction condition by number of extinction trials $(F=2.25, \mathrm{~d} I=36 / 360, \mathrm{P}<.01)$. The interprotation of this interaction can be gleaned from Figures 1-7. It is ab- 
vious that $C_{10}$ drank an equal amount of saccharine on sach of the seven test days." Also they drank more than either. $C_{1}$ or $C_{5}$ probably as a function of being at least 10 days older and thus heavier. of greater interest is the fact that $\mathrm{CS}_{5}$ and $\mathrm{CS}_{10}$ are significantly recovered from their arersion to saccharine at the outset of the test phase. This is not the case for the USs and Rs that had received five or 10 extinction trials. $C_{1}$ recovers during the test phase but at the same rate as $\mathrm{US}_{1}$. However, $\mathrm{CS}_{1}$ never recovers to the level of $\mathrm{CS}_{5}$ or $\mathrm{CS}_{10}$. These figures also indicate, as noted above, that the rate of recovery for US 5 and $\mathrm{US}_{10}$ appears to be potentiated by tho non-contingent IICl injections relative to the $R \mathrm{~s}$ which received no extinction treatment. 


\section{DTSCUSSION}

Interpretation of Acquisition Results

The results deplcting the amount of saccharine consumed by the three control groups on each of the three acquiation asasions indicates an initial neophobia for the saccharine. On the second and third acquisition trials, the C's significantly increased their ingestion of gaccharine (refer to the acquisition data of Table 2). These results are consistent with those raported by Nachman and Jones (1974) who interpret the initial aroldance as supportive of the leamed safety hypothesis. That is, the rats restrict their intake of saccharine until the consequences of ingegtion become obvious. When no iliness occurs the rats increase their consumption of the norel food.

In sharp contrast to the ingestion pattern exhibited by the $C$ 'g the expeximental subjects significantly decrease their saccharine consumption on the second and third acquisition trialo (They do evidonce a neophobia for the novel golution on the rirat trial, however). 
The decreased consumption of ssecharine by groups CS, US and $R$ on sessions two and three is consistent with the results from the classical conditioning literature on unprepared learning and was expected because they were injected with LiCl after they drank saccharine.

In the literature relating to the acquisition of a classically cenditioned response two points are consistently conIirmed. First, before a CS can elicit a CR the CS must be repeatedily paired with the US. Second, not only must there be repeated pairings of the CS and US; they nust be presented contiguously.

Although the data of this study does not provide evidence that is relevant to the equal associability of stimuli, the results are important to a discussion of the delay of reinforcement gradient. Conclusions based on classical conditioning of unprepared leaming lead to the prediction that conditioning would not occur where licl followed the saccharine because the ISI was two hours long. Hull (I952), White and Schlosberg (1952), and Gormezano and Moore In Marx (ed.), 1969 have determined that the optimal ISI for most response systems is 500 msec. Nuble and Adams (2963) and Nottermais, Schoenfeld and Bersh (1952) have described 
Iong ISI as 4,000 msec. ard thoo msec. rempectively. Young (1.958) was unable to pillary response with a $15,000 \mathrm{msec}$. ISI. The long delay of reinforconent (two hours) used in this study clearly indicates that at the very least the parameters that apply to the acquisition of unprepared reaponsea do not apply to prepared leamiug. This fact together with data reported elsewhere indicating that specific associations are established in preparsa learning (Garcia \& Koelling. 1967 and Kalat \& Rozin, 1971) provide efficient evidence to quegtion more than the range of ISI.

Kalat and Rozin (197I) propose to treat prepared learning as a biological characteristic of soms species, which is subject to natural selection and therefore adaptative. Prepared learning indicates the presence of special neural mechanisms which have developed because of important environmental problems (e.g. obtaining adequate foods). The same mechanisms involved in the acquisition of unprepared responses are probably involved in taste aversion learning, too. But, some stimuli are far more salient than others. This may mean that specific neural circuits and pathways associated with these stimuli and their potential consequence have 
2 lower threshold of excitability and a tendency, acquired through natural seled to rew active for a iong perjod of time when astivated by relevant afferents. A complete discussion of the CS, US and $R$ extinction results is of particular importance for an analysis of conditioned taste aversion relativ to prepared and unprepared learning. The results froin classical conditioning unprepared studies predicts that the CS procedure will be the only effective extinction technique. Every significant investigation involving prepared or unprepared learning indicates the superiority of this method. This is true of ail response systems across 2.13 species (Razran, 1939, Garcia, Erwin \& Koelling, 1966; Grote \& Browr, 1973). When the response is an appetitive on the extinction is usually complete. However, when an avoidance response is classically conditioned unprepared extinction is often only partial. Solomon and Wynne (1954) have reasoned that incomplete extinction of avoidance responses may be due to response conservation and partial irreversibility. Response conservation refers to the inferred state of anxiety that 3 a assuined to result from the presentation of the aversive CS. As the aversive conditioning progresses, the subjects iatency to emit the conditioned 
avcidance response decirdstes. The thency to respond is also short on most extinction trials suggesting that the fear component may not be available to extinguish. When the latency to reapond following the CS presentation is long, as it is on some trials, fear is assumed to be present from the behavior of the subject and is reduced by avoiding. This inferred process is offered by solomon and Wynne to account for the persistant responding in the absence of the US. Blocking which forces the subject to experience both the external CS and the inferred iear does result in extinction (Schiff, Smith \& Prochaska, 1972) and supports the analysis of response conservation. Bolles (1970) has concluded that all avoidance learming is of the prepared variety thus, Sclomon and Wynne's (1954) analysis has scme relevance to the results reported here. The classical conditioning unprepared literature is also consistent relative to the decay of the essociation established in avoidance learning. Marx (1969) reports that the evidence always supports the superiority of repeated CS preeentations ovar forgetting (trace decay as a function of disuse). Furthernore, Skinner (1960) has ursinatically shom the stability of associations over long 
periods. In a widely read paper, skinner showed that a spe-

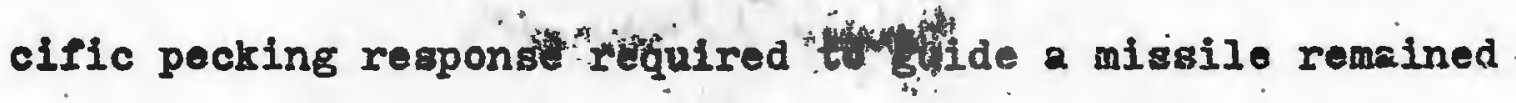
available to pigeons after a period of four years with no maintenance sessions following the acquisition of this response. Thus, from the unprepared leaming perspective the effect of the "retention" manipulation used in this study should have been minimal. This prediction contrasts with the analysis of adaptive behavior described by Kalat and Rozin (1971) and is contrary to the prediction that decay of the CS-US association would occur in this study.

The results described eariler show that the CS s do not fully recover to the level of the CBs. Recovery is substantial, however, and both of these facts are consistent with what is known about avoidance studies reported uncier the unprepared (Solomon \& Hynne, 1954) and prepared categories (Garci2, Erwin \& Koelling, 1966; Grote \& Brown1,1973). An analysis of the parametric efiects of the 1,5 and 10 extinction trials is also consistent with previously reported results in that a single CS presentation is ineffecilve. Five or 10 triale were equally effective which is somewhat surprising given the extent of the aversion to the saccharine (The test phase of Figuren 5-7 11lustrate these re- 
sults).

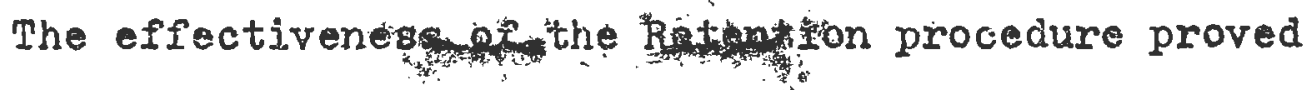
to be totally unsupportive of the hypothesis that conditioned taste aversions are acute rather than chronic. The complete absence of recovery for all subjects treated in the. retention manner shows that the association between the novel trste cue and the subsequent stomach malaibe does not deteriorate 2s a function of disuse, at Jeast this is not the case 20 days arter the last acquisition trial. These results are fully supportive of the predictions based on the unprepared classical conditioning evidence (Marx, 1969; Skinner, 1960). A test of the aversion after a retention interval considerably longer than 20 days might provide different results but this is mere speculation at this time. Finally, the partial recovery evidenced at the end of the seven day tost phase í not a good measure of an extended disuse perlod because decay was confounded with the CS extinction procodure since all rats drank at least some saccharine during the test phase.

The extinction procedure that utilizes the repeated presentation of the US alone (LiCl) provides some interestIng results that deserve space hers. The predictions about 
the effectiveness of this procedure were drawn from results reported in the unprepared learning area. Reynolds (1968) reports that the repeated presentation of the US alone after conditioning sensitizes the organism to the CS when it is presented again. A specific test of this prediction (Kimble, Mann and Dufort, 1955) supports Reynolds' generalization but data inconsistent with the Kimble et al. results have been reported (MCAllister \& McAllister, 1960). The prediction, relative to this study, was based on the sonsitization data. It was expected that rats having been repeatedly and non-contingently injected with IiCl would, on the subsequent test of the CS aversion show a persistent avoidance of the saccharine. In contrast Kalat and Rozin In Seligman \& Hager, 1972 have reasoned that a procedure that indicates to the rat that the saccharine did not produce the stomach malaise wiIl enhance recovery by producing cognitions inconsistent with the saccharine-illness attribution. Since repeated illness resulting from the non-contingent US injections provides information indicating that the initial novel stimulus-illness relationship was noncausa.I this procedure served as a test of Kalat and Rozin"s hypotinsis that conditioned taste aversion is a cognitive 
form of leaming. A single fout by Kalat and Rozin reported in seligman and other data that reflects on this point. These results were unsupportive of a cognitive interpretation of taste avoidance learning.

Although $\mathrm{CS}_{5}$ and $\mathrm{CS}_{10}$ were more effective extinction procedures than os extinction, 2 check of Figures 3 and 4 provides some evidence that the US procedure was at least partially effective. $U_{5}$ and $U S_{10}$ did consume significantly more saccharine than $\mathrm{CS}_{1}$, US $\mathrm{U}_{1}$ and all $\mathrm{R}^{\prime} \mathrm{s}$. Since it did result.in significantly more saccharine consumption relative to $R_{5}$ and $R_{10}$ one might conclude that repeated stomach malaise not associated. with the CS after conditioning tends to facilitate recovery from the conditioned avoldance when the CS is later presented. As an altermative to the possibility that US presentations enhance CR docrement (and entinction) as the MCAllisters' suggest, Kalat and Rozin's cognitive leaming hypothesis can presentiy incorporate the results of this stuoy. Data that support Kalat and Rozin's thesis are not in agreement with unprepared learning analysis. Unprepared learning theorists do not make reference to cognitiona but rely on more "primitive" 


\section{trits.}

learning mechanisms consisteritith unprepared learning

apply. But, when the rats are made repeatedly ill in the absence of saccharine after saccharine had been previously paired with LiCl an opportunity may exist for the rat to conclude that it could have been the case that the saccharine did not cause the illness. The first test of this cognition occurs when the rat is presented the saccharine solution on the first test day. Since the rat does not become ill subsequent to this test trial the cognition is confirmed and recovery (extinction) is expedited.

The results based on the CS and $R$ procedures fully support the conclusion that the extinction of a conditioned taste aversion parallels the elimination of an unprepared response. However, the US data do not appear to support the general finding that US presentations after conditioning enhances the aversion to the CS when it is subsequently reintroduced (Kimble et. al., 1955). There is some evidence for CR decrement following this procedure, however (Mallister \& Mchllister, 1960) and should further investigations corroborate the latter findings the US results of this study might also be incorporated into the unprepared learning category. 
APPENDIX A

Analysis of Variance of the Amount of Saccharine Consumed on the Three Acquisition Trials for All Groups of Rats.

\begin{tabular}{|c|c|c|c|c|}
\hline Source & $\begin{array}{l}\text { Sums of } \\
\text { Squares }\end{array}$ & à & $\begin{array}{l}\text { Mean } \\
\text { Squares }\end{array}$ & $F$ \\
\hline Total & 3.513 & 215 & & \\
\hline Between Ss & 2.069 & 71 & & \\
\hline Extinction Cond. & 1.678 & 3 & 0.559 & $96.424^{*}$ \\
\hline Trials & 0.008 & 2 & 0.004 & $<1$ \\
\hline EC X Trials & 0.034 & 6 & 0.006 & $<1$ \\
\hline Error b & 0.349 & 60 & 0.006 & \\
\hline Within Ss & 1.444 & 144 & & \\
\hline Sessions & 0.261 & 2 & 0.131 & $36.278^{*}$ \\
\hline Seasiong $X$ EC & 0.704 & 6 & 0.117 & $32.583^{*}$ \\
\hline Seasions X Trials & 0.003 & 4 & 0.001 & $<1$ \\
\hline $\begin{array}{c}\text { Sessions X EC } \\
X \text { Trials }\end{array}$ & 0.035 & 12 & 0.003 & $<1$ \\
\hline Error & 0.439 & 12.0 & 0.004 & \\
\hline
\end{tabular}


APPENDIX B

Analysie of Variance of the Amount of Saccharine Consumed on the Seven Test Prials for AIl Groups of Rats.

\begin{tabular}{|c|c|c|c|c|}
\hline Source & $\begin{array}{l}\text { Sums of } \\
\text { Squares }\end{array}$ & $d f^{\circ}$ & $\begin{array}{l}\text { Miean } \\
\text { Squares }\end{array}$ & $F$ \\
\hline Total & 29.141 & 503 & & \\
\hline Between $\mathrm{Sa}$ & 16.457 & 71 & & \\
\hline Extinction Cond. & 12.143 & 3 & 4.048 & $122.667^{*}$ \\
\hline $\operatorname{Tr} 1 a 18$ & 1.191 & 2 & 0.596 & $18.061^{*}$ \\
\hline EC X Trials & 1.126 & 6 & 0.188 & $5.697^{*}$ \\
\hline Error $_{b}$ & 1.997 & 60 & 0.033 & \\
\hline Within Ss & & 432 & & \\
\hline Sessions & 0.604 & 6 & 0.100 & $25.000^{*}$ \\
\hline Sessions $X E C$ & 0.263 & 18 & 0.015 & $3.750^{*}$ \\
\hline Sossions X Prials & 0.063 & 12. & 0.005 & 1.250 \\
\hline $\begin{array}{l}\text { Sessions } X \text { EC } \\
X \text { Trials }\end{array}$ & 0.316 & 36 & 0.009 & $2.250^{*}$ \\
\hline Error & .1 .433 & 360 & 0.004 & \\
\hline
\end{tabular}




\section{APPENDIX C}

Analysis of Variance of the Amount of Saccharine Consumed on the Pirst Test Trial for All Groups of Rats.

\begin{tabular}{|c|c|c|c|c|}
\hline Solkäe & $\begin{array}{l}\text { Suns of } \\
\text { Squaxes }\end{array}$ & $d x^{\prime}$ & $\begin{array}{c}\text { Mean } \\
\text { Squares }\end{array}$ & $\mathrm{T}$ \\
\hline Ioted. & & 71 & & \\
\hline$\cdot$ & & & & \\
\hline Extinetion Cond. & 2.1 .20 & 3 & 0.707 & 21.2 .450 \\
\hline Trial.s & 0.116 & 2 & 0.058 & 11.600 \\
\hline IS $\times$ Triala & 0.269 & 6 & 0.045 & 9.000 \\
\hline Erxor & 0.293 & 60 & 0.005 & \\
\hline
\end{tabular}

A.1I. $R^{\prime} \Leftrightarrow<00 I$ 
REFERENCXS

Bolles, R. C., Species specific defensive reactions and avoldance learming. Psychological Review, 1970, 27, 3248.

Boneau, C. A., The effects of violations of assumptions underlying the $t$ test. Psychological Bulletin, 1960, 51, 49-64.

Braveman, N. S., Poisoned based avoldance learning with llavored or colored water in guinea pigs. Learning and Motivation, $1974,5,182-194$.

Breland, ${ } .$, \& Breland, M. The misbehavior of organisms. American Psychologist, 1961, 16, 681.

Davis, J. I.. \& Bures, J., Dismuption of saccharine-aversion learning in rats by cortical epread of depreasion in the CS US interval. Joumal of Comparative and Physiological Pgychologx, 1.972, 80, 398-402.

Domjan, H. CS preexposure in taste-aversjon learnings eflects of deprivation and proexposure duration. Iearning and inotivation, 1972, 3, 389-402.

Ester, W. K., She statistical approach to learning theory. In S. Koch (ed.) Psychology: \& Study os a Science Vol. II. New York: NeGraw-Hil1, 1959.

Garcia, J., Erwin, F. R., \& Koelling; R. A., Leaming with prolonged delay of xeinforcement. Psychonomic Science. $1966,5,121-122$.

Gareia, J., Green, K. F., \& MeGowan, B. K., X-ray as an olfactory stimulus. In C. Piaffman (ed.) olfaction and Teste, Proceedings or the thind intemational symposiun. Now Fork Rockexeller University Press, 1969.

Garcia, J., Kimeldorf, D. J., k kunt, E. I., The use of ioniging radiation a a motivating stimulus. Pgychological neview, 1961, 68, 383.

Garcia. J., Koolling, R. A. A compariton of aversions inauced by $x$-rays, toxing end aruge in the rat. Radiation Reserecin, 1967. Supp1. 2. 439-450.

Gatoja, J., MicGowan, B. K., \& Green, K. F., Biologiee 3 con-o atraints on contistoning. In A. H. Black and W. F. ProKasy (od.) Classica Conditioning II Current Research 
and Theory. New York: Appleton-Century-Crofts, 1972.

Gormezano, I., \& Moore, J. W., Classical conditioning. In M. H. Marx Learning, Processes. New York: The MacMillan Co., 1969.

Grote, F. W., \& Brown, R. T., Deprivation level effects extinction of a conditioned taste avergion. Learning and Motivation, 1973, 4. 314-319.

Hayes, H. I. Statistics. New York' HoIt, Rinehart and Winston, 1963.

Hengfler, S., Conditioned avergion to external stimuli resulting fron delayed malaise. Paper presented at the annual meeting of the Easterm Psychological Association, Philadelphia, Pennsylvania, 1974.

Hilgard, E. R., \& Bower, G. H., Theories of Learning (3rd. ed.). New Yorks Appleton-Century-Crofts, 1966.

Hull, C. L., A behavior system. New. Haven. Yale University Press, 1952.

Hunt, E. L., Carroll, H. W., \& Kimoldorf, D. J., Humoral mediation of radiation-induced motivation in parabiont rats. Sctence, 1965, 150, $1747-1748$.

Kalat, J. W., \& Rozin, P., "Salience", A factor which carn overide temporal contiguity in taste aversion learning. Journal of Comparative and Physiological Psychology, $1970,21,192-197$.

Kalat, J. W., \&.Rozin, P., Specific hungers and poison avoidance as adaptive specializations of leaming. Psychological Review, 1971, 78, 459-486.

Kalat, J. W. : a Rozin, P., You can lead a rat to poison but you $\operatorname{can}^{\text {'t }}$ make him think. In M.E. P. Seligman and J. L. Hager (ed.) Bfological Boundarles of Learning. New York 1 Apploton-Century-Crofts, 1972.

Kalat, J. H. \& Rozin, P. "Laamed safety" aа \& mechaníg in long-delay taste aversion learning in rats. Journal of Comparative and Physiological Psychology. 1973.83.

Kimbles $G_{0} A_{0}$ : Hilgaxd and Marquig Conditioning and Learninf (znd. d.). New York kppleton-Century-Crofts, 1961. 
Kimble, G. A., Mann, I. I., fle Dufort, R. H., Classical and Instrumental eyelid conditioning. Joumal of Experimental Psychology, 1955, 49 , 407 - $417 \%$

Lang, P. J., Fear reduction and fear tbehaviors problems in treating a construat. In J. M. Solien (ed.) Research Psycho-theraoy, 1968, 3, 90-102.

Iang, P. J., \& Lazovik, A. D., Experimental desensitization of 2 phobia. Journal of Abnormal and Social Psychology. $1963,66,519-525$.

Lettvin, J. Y., Maturana, H, R., Fitts, H. H., \& McCullock, W. S., Two remarks on the vigual system of the froE. In W. A. Rosenbleth (ed.) Sengory Communication. Cambridge, Mass., 1959.

Levis, D. J., \& Cannera, R. N., Effects of ten hours of inplosion therapy in the treatment of outpatients. journal of Abnormal Psychology, 1967, 22, 504-508.

Iindquist, E. F., Design and analysis of experiments in psychology and equcation. Boston. Houghton Mifflin, 1953.

Iorden, J., Kenfield, M., \& Braun, J., Response suppression to odore paired with toxicosis. Leaming and Motivation, 1970, I. 391-400.

Iorenz, K. Z.. The comparative method in studying innate behavior patterns, 1950, 4, 221-268.

McAllister, W. R., \& MCAllister, D. E.. The influence of the ready signal and unpaired UCS preaentation on eyelid conditioning. Journal of Experimental Psychology, 1960, 60. 30-35.

Miller, H. R., \& Nawas, M. M., Control of aversive stimulus termination in systematic desensitization. Behavior Research and Therapy. 1969, 2, 57-61.

Morrison, G. R., \& Collyer, R., Taste-mediated conditioned averaion to an exteroceptive stimulus following IiC.l poigoning. Joumal of Comparative and Physiological Psyshology, $2974,86,51-55$.

Nechnan, il., \& Jones, D. R., Iearmed taste averzion over long delaya in rates the role of learned safety. Journal of Comparative and Fhysiological Ysychology, 19.74, 88, $949-956$.

Noble, M., \& Adams, $C . M$. , The effect of length of CS-US interval a a function of body temperature in a coldblooded animi. Journal of Genetic Psychology, 1963. 69. $1.97-201$. 
Norton, D. W. An empirical investigtion of some effects of non-normality and heterogeneity of the F-distribution Unpublished doctoral dissertation, State University of Iown, 1952.

Notterman; J. M., Schoenfeld, W. N., \& Berah, P. J., Conditioned heart rate responses in human beings during experimental anxiety. Joumal of Comparative and Physiological Psychology, 1952, 45, 1-8.

Parlov: I. P., Iectures on Conditioned Reflexes. Ner York: Intemational Publishers, 1928.

Razran, G., Studies in Configural Conditioning, VI, Comparative extinction and forgetting of pattern and of ainglestimulus conditioning. Journal of Experimental Psychology. 1939. $24,432-438$.

Revusky, S. H., Aversions to sucrose produced by contingent $x$-irradiation. Temporal and dosage parameters. Joumal of Comparative and Physiological Psychology, $1968,65,17-2 \hat{2}$.

Revusky, S. H, \& Bedarf, E. H, Associations of illness with prior injestion of novel foods. Science, 1967, 155. 219-220.

Revusky, S. H., \& Garcia, J., Leamed associations over long delays. In Bower, G. H. (ed.) The Psychology of Leaming and Motivation. (Vol.4) New Yorks Academic Press, 1970.

Reynolds, G. S., A primer of operant conditioning. San Diego: Scott Foresman and Co.

Rozin, P.. Central or peripheral mediation of learning with long CS-UCS intervals in the feeding sygtem. Joumal of Comparative and Physiological Psychology, 1969, 61, 421429.

Rozin, P., \& Rodgers, W., Novel-diet preferences in vitamindeficient rats and rats recovered from vitamin deficiencies. Joumal of Comparative and Physiological Psychology, 1967. 63, 429-433.

Rozin, P., \& Ree, P., Iong extension of effective CS-lis interval by anesthesia between CS and US. Journal of Comperative and Physiological Psychology, 1972, 30, 43-48.

Schiff, R, Smith, N., \& Prochaska, J., Extinction of avoidance in rats $2 s$ a function of duration and number of blocked trials. Joumal. of Comparative and Fhysiological Psychology, 1972, 81, 356-359. 
Seligman, M. E. P., On the getherzilty of the laws of learming. Psychological Revieg, 1970, 27, 406-418.

Seligman, M. ${ }^{2}$. P. , Phobias and M. E. F. and Hager, J. I. Biological Boundaries of Learning. New York, Appleton-Century-Crofts, 1972.

Seligman, M. E. P., \& Hager, J. I. Biological Boundaries of Learming. New York, Appleton-Century-Crofts, 1972.

Skinner, B. F., A case history in scientific method. In S. Koch (ed.) Psychology- $\hat{h}$ Study of a Scjence. New York, MicCraw-Hill Book Co., 1959, 2.

Skinner, B. F., Pigeons in a pelican. American Psychologist, $1960,1.5 .28-37$.

Smith, D. F., \& Balagura, S., Role of oropharyngeal factors in IiCl aversion. Joumal of Comparative and Physiological Paychology, $1969,69,308-310$.

Smith, J. C., \& Ro11, D. I., Trace conditioning with x-rays as the aversive stimulus. Psychonomic Science, 1967, 2 . 1.1-12.

Solomon, R. I., Wymne: I. C., Traumatic avoidance locrning, The principle of anxiety conservation and partial irreversibility. Psychological Review, 1954, 61, 353-385.

Thorndike, E. I., Reward and punishment in animal learning. Comparative Fsychology Monograph, 1932, 8, no. 39.

White, C. T. \& Schlosberg, H., Degree of conditioning of GSR as a function of the period of delay, Journal of Excerinental Psychology, 1952, 43. 357-362.

Hiner, B. J., Statistical principles in experimental design. New York: McGraw-Hill Book Co., 1971.

Young, E. A., Studies of pupillary conditioning. Joumal of Exporimental Psychoiosy. 1958, 55, 9?-110. 